\title{
De enquête van Oudenburg. Hervorming van de repartitie van de beden in het graafschap Vlaanderen (1408)*.
}

\author{
W. Buntinx \\ Aspirant N.F.W.O.
}

Vanaf het midden van de XIVe eeuw was men in Vlaanderen de verhoudingen van de kwoten van het Transport (I) beginnen aan te wenden om een billijke en steeds gelijkvormige verdeling van de beden over het graafschap te verkrijgen. Dit was o.a. nog het geval voor een bede van 1367-1368; voor de bede van 13771378 echter niet meer (2) en deze tendens zou zich naar

(*) Voor de verwezenlijking van deze bijdrage en tekstuitgave danken we in het bijzonder prof. E. I. Strubbe, wiens kostbare suggesties ons uiterst nuttig waren.

(I) Een belasting van $8.000 \mathrm{lb}$. par. op Vlaanderen, ontstaan uit de bepalingen van de verdragen van Athis-sur-Orge (1305) en van Pontoise (1312). - F. Funck-Brentano, Philippe le Bel en Flandre. Les origines de la guerre de cent ans. Thèse., Parijs, I 896 ; p. $48 \mathrm{I}$ e.v. - H. VAN WERveKe, Les charges financières issues du Traité d'Athis (1305), in Revue du Nord, bd. XXXII, 1950, pp. 8I-93. $\mathrm{R}$. Monier, Les institutions financières du comté de Flandre. Du $X I^{e}$ siècle à 1384., Parijs, I948; p. 25.

(2) W. PREVENIER, De beden in het graafschap Vlaanderen onder Filips de Stoute (1384-1404), in Belgisch Tijdschrift voor Filologie en Geschiedenis, bd. XXXVIII, nr. 2, 1960, pp. 330-365; pp. 344345 . 
het einde van de XIVe eeuw toe nor versterken. Steeds meer bezwaren rezen tegen het verdere gebruik van het Transport ter verdeling van beden. De oorzaken hiervan waren sterk uiteenlopend: de algemene ekonomische en agrarische depressie van de tweede helft van de XIVe eeuw en de oorlogen, de epidemieën (I) en in het bijzonder de overstromingen in de kuststreek met als dieptepunt I375-I376 (2). Het geheel van deze feiten en toestanden bracht een sterke verschuiving teweeg in de ekonomische en demografische verhoudingen tussen de Vlaamse steden en gebieden. Bijgevolg stemden de verhoudingen, opgemaakt uit de cijfers van het Transport van Vlaanderen, helemaal niet meer overeen met de werkelijke toenmalige toestand. Men moest dus bij iedere bede een nieuwe repartitie opstellen.

Een eerste poging om deze wantoestand te verhelpen ging uit van hertog Filips de Stoute. In een mandament (I3 jan. I395, n.s.) (3) beval hij een onderzoek in te stellen naar de mogelijkheden een nieuwe repartitietabel op te stellen, vooral voor het Brugse Vrije, en duidde terzelfdertijd vier kommissarissen aan om deze taak uit te

(1) J. A. VAN Houtte, Ekonomische en sociale geschiedenis van de Lage Landen, Zeist-Antwerpen, I964; pp. 80-8I. - A. VerhuLST, L'économie rurale de la Flandre et la dépression économique du Bas Moyen Age, in Etudes rurales, nr. Io, 1963, pp. 68-80 \& in Studia historica Gandensia, nr. 7, I964; pp. 70-72. - H. VAN WERVEKE, De Zwarte Dood in de Zuidelijke Nederlanden (1349-1351), (Med. Kon. V1. Ac. Wet., Let., Sch. K., kl. Let., jrg. XII, I950, nr. 3).

(2) M.K.E. GotrschalK, Historische Geografie van westelijk Zeeuws-Vlaanderen, 2 dln., Assen, 1955-1958; dl. I, pp. I59-163 \& p. I92.

(3) B. RA, Registers van het Brugse Vrije, nr. I (Wittenbouc), fo 61. - ed. F. Priem-O. Delepierre, Précis analytique des documents que renferme le dépót des Archives de la Flandre-Occidentale à Bruges. II érie., 9 dln., Brugge, I843-1 858 ; dl. VI, pp. 135-I 38. 
voeren (I). Doch in de volgende jaren hoorde men van dit onderzoek niets meer. De geweldige Sint-Elizabethsvloed van I9 december $\mathrm{I}_{404} \mathrm{O}$ in de kuststreek maakte de toestand nog meer precair (2).

De onmiddellijke aanleiding tot de herziening van het Transport in 1408 was een bede van 108.000 dubbele schilden, die de Vier Leden van Vlaanderen, Gent, Brugge, Ieper en het Brugse Vrije, aan hertog Jan zonder Vrees in I407 hadden toegestaan. De afbetaling zou geschieden in verschillende termijnen. Voor de eerste termijn van Kerstmis 1407 werd algemeen uitstel verleend wegens de slechte toestand van vele gebieden. De volgende termijn verviel op Sint-Jansmis (24 juni) I408. De bede zou ghestelt ende ghepoint werden naer transport ende niet anders (3). De uitvoering stuitte echter op allerlei moeilijkheden.

De beweegredenen, waarom men tenslotte toch tot een herziening van de repartitiebasis overging, worden uiteengezet in een kommissie-oorkonde van Jan zonder Vrees van 20 juli I408 (4). In dezelfde oorkonde wordt een college van zeventien leden aangesteld, belast met het onderzoek en de redaktie van een nieuwe percentsgewijze repartitietabel voor een verdeling over de "onafhankelijke" steden en over de kasselrijen. Van deze zeventien personen fungeren er negen als kommissarissen van de hertog en acht als gedeputeerden van de Vier Leden, voor elk Lid twee. Onder de negen kommissarissen van de hertog telde men (5):

(I) Nl. : Jan de Visch, heer van Cappelle, Hendrik van Mortagne, heer van Spiere, Sander Spierinc en Pieter Heyns. Voor identifikatie, zie index.

(2) M.K.E. Gottschalk, o. c., I, pp. 20I-203.

(3) G. RA, Land van Waas, nr. I38 (1 407, 3 I december).

(4) Uitgegeven, infra, als tekst $I$.

(5) Voor verdere identifikatie, zie index. 
3 edellieden en ridders :

- Jan de Visch, heer van Cappelle, vroeger soeverein-baljuw (I386-I390).

- Monfrant van Eessene, vroeger soeverein-baljuw (I403-I405).

- Jacob Belle.

2 leden van de fiskale administratie :

- Andries van Douay, ontvanger-generaal van Vlaanderen en Artesië.

- David Bousse, meester van de Rekenkamer te Rijsel.

4 baljuws :

- Robrecht van Cappele, baljuw van Brugge.

- Dankaard van Ogierlande, baljuw van Gent.

- Jan van den Kerchove, baljuw van Aalst.

- Jan de Hond, baljuw van Beveren-Waas, tevens burggraaf en ontvanger.

De deputatie van de Vier Leden was samengesteld uit :

2 heren en ridders :

- Boudewijn de Vos, heer van Pollare (Brugge).

- Jan Belle, heer van Boezinge (Ieper).

6 leden van stads- of kasselrijbesturen of vooraanstaande poorters :

- Victor van der Zickelen (Gent).

- Lieven Papal (Gent).

- Lieven de Scuetelare (Brugge).

- Andries Paeldinc de Oude (Ieper).

- Gillis van der Kercstede de Oude (Brugse Vrije).

- Willem van Messeem (Brugse Vrije). 
De plaats, waar dit college samenkwam en zijn besprekingen voerde, was de stad Oudenburg bij Oostende, zodat men later de hernieuwde repartitie van $1408 \mathrm{zal}$ heten : het Transport van Oudenburg.

Om te beginnen stelden voornoemde afgevaardigden de werkwijze vast (I). Men legde er nog eens de nadruk op dat alleen het Transport, als repartitietabel voor beden en subsidies, zou gewijzigd worden, dus N I E T het Transport als jaarlijkse belasting. Vervolgens vroegen de Vier Leden aan de steden en kasselrijen van Vlaanderen, hun schriftelijk een verslag over te maken over de toestand in de respektieve gebieden. Elk van de Vier Leden centraliseerde de verslagen van zijn kwartier (2). Deze verslagen werden dan te Oudenburg gezamenlijk door de afgevaardigden, daartoe aangesteld, besproken. Het geheel van dit onderzoek kreeg de vorm van een enquête, waarbij de nadruk werd gelegd op de gevolgen van natuurrampen, oorlogen en ontvolking; in detail voor het Brugse Vrije, de Vier Ambachten, het Land van Waas en Biervliet, meer algemeen voor de overige gebieden.

De werkzaamheden te Oudenburg werden beëindigd op 9 september 1408 . In een slotverklaring werd al wat voorafging samengevat en bevestigd door alle afgevaardigden.

Eens dat de repartitie van het algemene Transport herzien was, kon men beginnen de partikuliere Transporten te wijzigen. Dit was een operatie van lokaal belang, weliswaar onder de kontrole van de hertog en de Vier Leden, doch die niet in de bevoegdheid van het college te Oudenburg viel (3).

(I) Zie tekstuitgave, tekst 5, § I en 2, Pp. IoI-IO4.

(2) G. RA, Land van Waas, nr. 138 (I 408, I 2 augustus).

(3) A. RA, Rekenkamer, nr. I 244. 
DE ENQUÊTE-ROL VAN I 408.

De resultaten van de Transporthervorming werden opgetekend op een rol, waarvan vijf gelijkluidende eksemplaren werden vervaardigd: één voor de hertog en gedeponeerd in de Rekenkamer van Rijsel; en voor elk van de Vier Leden één (I). Dit gebeurde op 9 september I408, bij de slotvergadering te Oudenburg. De rol werd bekrachtigd door de zegels van al de kommissarissen en gedeputeerden, waardoor ze ook voor de hertog geldig werd geacht.

De rol bevat negen paragrafen van uiteenlopende aard :

I. Algemene principes en werkwijze door de kommissie van Oudenburg toegepast (Middelnederlands).

2. Vergoeding van de kommissarissen en gedeputeerden - kosten, welke nodig waren om het onderzoek ter plaatse uit te voeren en de besluiten ervan over te brengen naar Oudenburg - kosten om deze rol op te stellen - alles samen : 3.4Io $\mathrm{lb}$. par. (Middelnederlands).

3. Kopie van de kommissie-oorkonde van Jan zonder Vrees van I5 juli 1408 : waarom een nieuwe repartitie? - methodes, die aangewend moeten worden - aanstelling van de onderzoekskommissie (Frans).

4. Kopie van de kommissie-oorkonde van 5 september 1408 van de stad Gent voor haar twee gedeputeerden : bekrachtiging door de nieuw aangestelde schepenen (Middelnederlands).

(I) Zie de tekstuitgave van deze rol, tekst 5, §9-- technische en materiële gegevens : zie kritisch apparaat vóór de uitgave - G. $\mathrm{SA}_{\mathrm{A}}$, serie 93bis, nr. I (Wittebouc), fo I63v. 
5. Kopie van de kommissie-oorkonde van 2 september 1408 van de stad Brugge voor haar twee gedeputeerden: bekrachtiging door de nieuw aangestelde burgemeesters en schepenen (Middelnederlands).

6. Redenen waarom de stad Ieper en het Brugse Vrije geen bekrachtiging afleverden voor de aanstelling van hun respektieve gedeputeerden (Middelnederlands).

7. Verslag en resultaten van de enquête en de beraadslagingen over de hernieuwing van de procentuele algemene repartitie (Middelnederlands).

8. Kopie van een oorkonde van 3 I augustus I408, waarbij hertog Jan zonder Vrees een bede van 20.000 dubbele schilden oplegt aan het graafschap Vlaanderen, uitgezonderd de Vier Leden, om de kosten te vergoeden, welke de Vier Leden de laatste jaren gedaan hadden voor het algemeen welzijn van Vlaanderen (Frans).

9. Samenvatting, slotbeschouwingen en bekrachtiging van al het voorgaande door de I7 afgevaardigden te Oudenburg (Middelnederlands).

Het centrale en omvangrijkste gedeelte van deze rol is $\S 7$, waarin men het verslag en de resultaten vindt van de enquête en het onderzoek naar aanleiding van de repartitiehernieuwing. Deze paragraaf kan men eveneens onderverdelen in verschillende kapittels. Telkens echter vindt men hetzelfde schema weer: de oude procentuele kwote in het Transport, de reden(en) van verandering, de vermeerdering of vermindering, de nieuwe procentuele kwote. Men onderscheidt in $\S 7$ zes kapittels :

I ${ }^{\circ}$ De steden, die voorgoed verdronken zijn en dus niets meer moeten betalen. Er wordt echter niet vermeld 
wanneer ze verdronken zijn : in feite is dit het resultaat van twee overstromingsgolven, I375-I376 en 1404 .

$2^{\circ}$ Meer gedetailleerd verslag van het onderzoek en de resultaten ervan, in het kustgebied van het Brugse Vrije, de Vier Ambachten, het Land van Waas en Biervliet.

\section{a) Brugse Vrije:}

onderzoek per ambacht in IJzendijke -, Oostburg -, en Aardenburg ambacht.

onderzoek van het duinengebied en eraan grenzend bouwland van Knokke tot Oostende.

Telkens wordt in detail de grootte en oppervlakte in gemeten van de verdronken of onbebouwbare gebieden opgegeven, de oorzaken van het verlies, de plaatsen waar dit gebeurd is en wat dit tenslotte vertegenwoordigde in de kwoten van het Transport.

b) Vier Ambachten:

zelfde methode als voor het Brugse Vrije, nl. onderzoek per ambacht. Voor Boekhoute ambacht nog onderverdeeld in zeven besetten.

c) Land van Waas :

de lokaliteiten die om één of andere reden verliezen hebben geleden.

d) Biervliet en aangrenzende gebieden.

$3^{\circ}$ Steden en kasselrijen die verarmd zijn en bijgevolg hun kwote tegenover het Transport verminderd zien.

$4^{0}$ Steden, waarvan de kwote ongewijzigd bleef.

$5^{\circ}$ Steden en kasselrijen, waarvan de kwote verhoogd werd.

$6^{\circ}$ Steden en gebieden, die vroeger niet meebetaalden in het oude Transport, maar ditmaal wel aangerekend werden. 
Het verslag van het onderzoek in het Brugse Vrije, de Vier Ambachten, het Land van Waas en Biervliet is van zeer groot belang voor de geschiedenis van de overstromingen in het Vlaamse kustgebied. In deze bron worden de plaatsen opgesomd, die zwaar geleden hebben of helemaal verloren zijn gegaan. Aan de hand van kronologische gegevens uit andere bronnen kan men dan bepalen wanneer de respektieve overstromingen plaats hebben gehad. Wat echter zeer interessant is, is de aanduizing van de oppervlakte van de verloren gebieden: dit zijn weliswaar schattingen, maar geven ons toch een globaal beeld van de landverliezen: zo blijft er in I408 van IJzendijke ambacht slechts I/ro over en van Boekhoute ambacht slechts I/4; het overige was door de zee verzwolgen. Voor het gebied tussen de monding van het $Z$ win en Oostende duikt een ander verschijnsel op : in dit gebied is het niet zozeer het zeewater dan wel de verstuiving van duinzand landinwaarts, die vele nederzettingen onbewoonbaar en veel landbouwgrond onbebouwbaar heeft gemaakt. Het geheel van deze enquête geeft een globaal beeld van de ekonomische en demografische verhoudingen, die in het begin van de XVe eeuw in Vlaanderen heersten. Nochtans mag men het beeld, dat men hiervan zou krijgen, niet kritiekloos opnemen. In de XVe eeuw was men immers met de toenmalige middelen en kennis niet in staat de ekonomische betekenis van verschillende gebieden tegenover elkaar nauwkeurig in cijfers vast te leggen. Men ging proefondervindelijk te werk en dikwijls speelde de intuïtie een grote rol. Het is dus normaal dat er een aantal misvattingen voorkwamen. Bovendien moet men er ook rekening mede houden, dat ook de politieke machtsverhoudingen hun invloed lieten gelden. Zo staat Brugge in het Transport hoger aangeslagen dan Gent; in 1408 vermeerdert de kwote van Brugge nog en die van Gent vermindert 
een weinig. Dit weerspiegelt echter helemaal niet de ekonomische machtsverhoudingen van beide steden. Immers in het begin van de XVe eeuw was Brugge reeds gevoelig acheruitgegaan en teerde nog op zijn macht van een eeuw tevoren, terwijl Gent niet dezelfde tendens gekend had.

Nochtans betekende de hervorming van 1408 een grote vooruitgang en modernisatie op fiskaal gebied : de methodiek, die men in het onderzoek weervindt, wijkt reeds hemelsbreed af van de occasionele methodes van de middeleeuwen en wijst reeds op de komst van een nieuw tijdsbeeld. Het aanwenden van een vaste repartitiebasis voor de verdeling van willekeurige beden laat toe een billijke en steeds gelijkvormige verdeling op te stellen, zodat bovendien langdurige en moeizame besprekingen worden uitgesloten, tenminste zolang de cijfers van het Transport overeenstemmen met de werkelijke omstandigheden. Ook de hervorming van 1408, het Transport van Oudenburg geheten, onderging het lot van zijn voorganger en werd mettertijd onbruikbaar, zodat een vernieuwing zich opdrong. Men moest echter nog wachten tot $15 \times 7$, vooraleer het zover kwam.

UITGAVE VAN DE ROL VAN DE ENQUÊTE VAN I408.

Tekstrraditie. Van de rol van de enquête van 1408 , waarvan oorspronkelijk vijf eksemplaren bestonden, is er slechts één origineel bewaard, nl. de ekspeditie bestemd voor het Brugse Vrije. Bovendien zijn er nog enige kopieën bewaard. Uit deze kopieën blijkt dat de originelen wel degelijk al ghelijc geweest zijn. Het enige, waarin de afschriften van het bewaarde origineel verschillen is de orthografie van de woorden, wat trouwens zeer normaal is, daar de orthografie kon verschillen van scribent tot scribent. Er zijn echter geen noemenswaardige verschillen van textuele aard aan te stippen. Voor een vijftiendeeuwse 
tekst heeft het geen zin de orthografische varianten aan te duiden. Enkel voor, door beschadiging, onleesbare woorden werd beroep gedaan op de afschriften.

WijZe van uitgave. In de uitgave werd de oorspronkelijke rangschikking van de verschillende teksten gewijzigd en kronologisch geordend, volgens de datum van het origineel. De interpunktie en het gebruik van hoofdletters werden genormaliseerd volgens hedendaags gebruik. De tekst werd identiek weergegeven zoals in het origineel, terwijl alle afkortingen opgelost werden. Slechts de aaneengevoegde woorden, die konden gescheiden worden zonder het woordbeeld te wijzigen, werden gescheiden volgens moderne normen, bv. vanden werd aldus van den. Hetzelfde gebeurde ook in tegenovergestelde zin, bv. hier na werd aldus hierna. De $u$ van het origineel werd eveneens genormaliseerd tot $u$ of $v$ volgens hedendaags gebruik. Deze regels werden ook in acht genomen voor de Franse teksten. Het afkappingsteken werd hierbij gebruikt zoals tegenwoordig. Aksenten werden echter niet geplaatst, tenzij het aksent op de lange en klare $\dot{e}$ op het einde van een woord, om ze te onderscheiden van de doffe $e$. Voor de identifikatie en situering van persoonsen plaatsnamen verwijzen we naar de index, achteraan in de uitgave.

Hertog Jan zonder Vrees heeft van de Vier Leden van Vlaanderen de toestemming gekregen om, ter gelegenheid van zijn blijde intrede als graaf van Vlaanderen, een bede te heffen van 108.000 dubbele schilden. Deze bede had in 
de eerste plaats tot doel de handelsbetrekkingen van Vlaanderen met Engeland te helpen verbeteren. Normaliter zou deze som, zoals het de gewoonte was, over het land verdeeld worden volgens het "oude" Transport van Vlaanderen. Daar echter de toestanden en verhoudingen sedert het ontstaan van het "oude" Transport totaal veranderd waren, vooral door overstromingen en oorlogen, werd besloten deze bede te verdelen volgens een nieuwe repartitieschaal. Het onderzoek, de bespreking en de redaktie van deze nieuwe verdelingswijze zouden uitgevoerd worden door 9 kommissarissen van de hertog en 8 gedeputeerden van de Vier Leden, voor elk Lid twee gedeputeerden.

\section{Gent, 20 juli I408.}

$A$. Origineel. Niet voorhanden. Het droeg volgens $B^{1}$ op de rug volgend opschrift: " le VIIe jour d'aougst l'an mil CCCC et huit, les conseilliers et autres commissaires de monseigneur le duc de Bourgoingne, conte de Flandres, d'Artois et de Bourgoingne, etles nommez et deputez des bonnes villes et terroier firent le serrement, present monseigneur de Courtivron, chancellier de mon dit seigneur, de faire et acomplir le contenu au blanc de ces presentes a leur povoir et sentement, moy present, J. de Saulz".

$B^{1}$. AfsCHRIFt van 9 september I $_{4} 08$; als $\S 3$ van de enquêterol van 1408 , ekspeditie voor het Brugse Vrije (uitgegeven als tekst 5) ; naar $A$. - B. RA, Charters van het Brugse Vrije, nr. 279.

$\left[B^{2}-B^{3}-B^{4}-B^{5}\right.$. Afschriften; ekspedities respektievelijk voor de stad Brugge, de Rekenkamer van Rijsel, de stad Gent en de stad Ieper. Niet voorhanden. Naar $A$.]

$C^{1}$. Afschrift, s. XV m., in een papieren register (20 fo) met als titel : "Den transpoort van Vlaendren vernieud int jaer VIII ", fo 2-3 v ; naar $B^{\mathbf{1}}$. - B. RA, Registers van het Brugse Vrije, nr. 587 .

$C^{2}$. Afschrift, s. XV in., in de Ouden Wittenbouck van de stad Brugge, fo $149 \mathrm{~V}-15^{\circ}$; naar $B^{2}$. - Stadsarchief van Brugge. $D^{2}$. Afschrift s. XV ex., in de Groenen Bouck $B$ van de stad Brugge, fo $289 \mathrm{v}-290$; naar $B^{2}$. - Stadsarchief van Brugge. 
$C^{3}$. Afschrift, s. XV, in een reeks losse dokumenten, achteraf samen ingebonden; katern 8 ; naar $B^{3}$. - A.D.N., série $B$, nr. 19.482 .

Uitgaven : a) F. Priem-O. Delepierre, Précis analytique des documents que renferme le dépót des Archives de la FlandreOccidentale à Bruges. II $I^{e}$ série., 9 dln., Brugge, I843-I858; dl. VI, pp. I 43-I 47 (naar ?). - b) L. Gilliodts-van Severen, Inventaire des Archives de la ville de Bruges. Section première. Inventaire des Chartes. I $\mathbf{e}$ série. $X I I-X V \mathbf{e}$ siècles, 9 dln., Brugge, I87I-I885; dl. IV, pp. 20-22 (naar $C^{2}$ ).

Jehan, duc de Bourgoingne, conte de Flandres, d'Artois et de Bourgoingnen palatin, seigneur de Salins et de Malines, a tous ceulx, qui ces presentes lettres verront, saluut.

Comme les bourchma[istres] $\left({ }^{a}\right)$, advoué, eschevins et consaulz de noz villes de Gand, de Bruges, d'Ypre et de nostre terroir du Franc pour eulx et tout le demourant de nostre pays de Flandres, tant pour et a cause de nostre joyeux ad[v]enne[ment] $\left({ }^{a}\right)$, et premiere entree comme conte et seigneur de nostre dit pays de Flandres, comme nous aydier a supporter les grans sarges, que depuis nous sont survenues et avons eu a soustenir pour le $\mathrm{f}[\mathrm{ait}]\left({ }^{a}\right)$ de la commune marchandise d'entre nostre pays de Flandres et cellui d'Engleterre et autrement en pluseurs manieres, nous aient liberament acordé et consenti ung ayde de la somme de cent et huit mille doubles escuz de nostre forge et nouvelle monnoie de Flandres. Et il soit ainsi, que depuis le dit acort nous aions volu faire asseoir et lever le dit ayde sur noz villes et chastellenies de nostre dit pays selon l'estat et faculté de chascune d'icelles, ainsi que feu nostre tres chier seigneur et pere, dont Dieu ait l'ame, souloit faire en cas parail ; pour laquelle cause les bonnes gens des loys de noz dites villes et terrouer

(a) Onleesbaar door beschadiging; hersteld aan de hand van $C^{1}$. 
nous ont humblement supplié par pluseurs fois, que il nous pleuist faire, asseoir et lever le dit ayde selon le taux du viel transport, pieça ordonné en nostre dit pays. E.t se nous avions aucune faute ou perte en nostre dit ayde, ilz estoient d'acort et consentement, que nous en feussions recompensez sur nostre dit pays tant et si avant, que nous aurions pleinement nostre dit ayde. Ce que a leur requeste leurs avons acordé de faire, mais depuis quant l'en y a volu proceder et faire l'assiete du dit ayde selon le dit viel transport ordonné, l'en a trouvé pleinement, que il ne fest peu ne pouroit faire bonnement, se premierement n'estoit sur ce pourveu et fait une nouvelle ordonnance justement et loyaument par laquelle chascune des dites villes et chastellenies de nostre dit pays peust payer sa part et porcion du dit ayde selon son estat et faculté, pour ce que depuis le dit viel transport ordonné pluseurs des villes et paroches et partie des chastellenies de nostre dit pays devers les merches de la mer sont tellement apovries et les aucunes du tout noyees et inundees de la dite mer et les autres diminuees et en voie de desercion, tant par le fait d'icelle mer comme par le fait des commotions, qui ont esté derreni[er]ement $\left({ }^{a}\right)$ en nostre dit pays de Flandres et autrement en pluseurs manieres, que elles ne pourroient en aucune maniere selon le dit viel transport supporter ne payer leur porcion du dit ayde; ainçois en seroient du tout desers et miz a destruction, sicomme ces choses et autres orıt esté nagaires et de nouvel remonstrees plus a plain par devant nostre amé et feal chanchelier, le seigneur de Courtivron et les gens de nostre conseil en la presence des lois de noz dites villes et terroir, pour sur ce pourveoir et faire la dite ordonnance et advis justement et loyaument, pour lever le dit ayde.

(a) Onleesbaar door beschadiging; hersteld aan de hand van $C^{1}$. 
Savoir faisons, que nous, ces choses considerees, voullans pourveoir a ycelles et eu regart aux inundacions et dommages dessusdiz, avons par grant avis et meure deliberacion de conseil et par le sceu des loys de noz dites villes de Gand, de Bruges, d'Ypre et de nostre dit terroir, pour ce assemblees pluseurs fois et journees avecq noz diz chancellier et conseil, ordonné et consenti, ordonnons et consentons par ces presentes, que une ordonnance et advis soient fais justement et loyaument, par quoy chascune de noz dites villes et chastellenies de nostre dit pays puissent paier sa porcion du dit ayde selon sa faculté sans estre grevee et les autres frais apparans, qui sont a lever pour le bien commun de nostre dit pays. Et pour ce faire nous, confians des loyautez, predommies et discrecions de noz amez et feaulx conselliers, le sire de la Chapelle, messire Monfra[nt] ( $\left.{ }^{a}\right)$ d'Essines et messire Jaques Belle, chevaliers, Robert de Capples, nostre bailli de Bruges, Andrieu de Douay, nostre receveur general de Flandres et d'Artois, maistre David Bousse, maistre de noz comptes a Lille, Dankaerd d'Ogierlande, nostre bailli de Gant, Jehan de Latre, nostre bailli d'Alost et Jehan le Chien, nostre chastellein, bailli et receveur de Bevre, yceulx tous ensamble, les sept ou les huit d'eulx, avons commiz et ordonné, commettons et ordounons, en leur donnant plain povoir, auctorité et mandement especial par ces meismes presentes, que au plus tost, que bonnement porront, en lieu convenable, tel qu'ilz aviseront et bon leur samblera, jlz se transportent et assemblent et illec appelles avecq eulx noz bien amez, Victor de le Faulchille, Lievin Papil, messire Bauduin le Vos, Lievin le Scotelare, le sire de Bousinghe, Andrieu Paeldinc le viel, Gille de le Kercstede le viel et Guillamme de Messein, deputez de par noz bonnes ville Gand, Bruges,

(a) Onleesbaar door beschadiging; hersteld aan de hand van $C^{1}$. 
Ypre et de nostre terroir du Franc et aussi de noz officiers des lieux et autres predommes en ce expers et telz que expedient sera, procedant diligemment et loyaument et par bon avis et meure deliberacion, de faire la dite ordonnance et imposer a chascune de noz dites villes et chastellenies sa porcion, telle qu'il leur semblera de raison en regart a toutes les choses dessusdites et autres adce servans au mieulx, le plus justement et loyaument, pourvue chascune de noz dites villes et chastellenies que faire le sauront ou pouront bonnement, en faisant lettres notablement soubz leur seaulx de la dite ordonnance, qu'ilz auront faite sur la dite destribucion. Lesquelles lettres nous confermerons par les nostres, se mestier est, affin que selon ce nostre ayde dessusdit puist estre assiz, distribué et levé sur toutes les villes et chastellenies de nostre dit pays, et les autres frais apparans, qu'il sont a lever pour le bien commun de nostre dit pays, comme dit est dessus. Si donnons en mandement par ces mesmes presentes a tous noz baillis, justiciers, officiers et subges de nostre dit pays et a chascun d'eulz, que a noz diz commiz ou aux huit ou sept d'iceulx obeissent pleinement et diligemment, car ainssi nous plaist il estre fait non obstans ordonnances, mandement ou deffenses a ce contraires.

En tesnioing de ce, nous avons fait mettre nostre seel a ces presentes. Donné a Gant, le $\mathrm{XX}^{\mathrm{e}}$ jour de jullet, l'an de grace mil CCCC et huit.

[Get.] Par monseigneur le duc vous present, J. de Saulz.

Jan zonder Vrees staat toe dat een bede van 20.000 dubbele schilden zal geheven worden, te verdelen, niet volgens het Transport, over geheel het graafschap Vlaanderen, uitgezonderd de Vier Leden. De opbrengst van deze bede 
is immers bestemd om de onkosten te dekken, die de Vier Leden gehad hebben bij hun streven naar betere handelsbctrekkingen met Engeland en bij het opstellen van een nieuwe repartitiebasis voor beden.

Kortrijk, 3I augustus 1408 .

$A$. Origineel. Niet voorhanden

$B^{1}$. Afschrift van 9 september 1408 ; als $\S 8$ van de enquêterol van 1408 , ekspeditie voor het Brugse Vrije (uitgegeven als tekst 5); naar A.-B.RA, Charters van het Brugse Vrije, nr. 279.

$\left(B^{2}-B^{3}-B^{4}-B^{5}\right.$. Afschriften). Zie I, ibidem.

$C^{1}$. Afschrift, s. XV m., in een papieren register (2o fo) met als titel: "Den transpuorl van Vlaendren vernieud int jacr VIII ", fo I 2v-r 3v ; naar $B^{1}$. - B. RA, Registers van het Brugse Vrije, nr. 587 .

$C^{2}$. Afschrift, s. XV in., in de Ouden Wittenbouck van de stad Brugge, fo $154 \mathrm{~V}$; naar $B^{2}$.-Stadsarchief van Brugge. $D^{2}$. Afschrift, s. XV ex., in de Groenen Bouck $B$ van de stad Brugge, fo 297 ; naar $B^{2}$.-Stadsarchief van Brugge.

$C^{3}$. Afschrift. Zie 1, $C^{3}$.

Uitgaven : a) F. Priem-O. Delepierre, Précis analytique, dl. VI, pp. I76-r 79. - b) I.. Gilliodts-van Severen, Inventaire, dl. IV, pp. 27-28 (naar $C^{2}$ ).

Jehan, duc de Bourgoingne, conte de Flandres, d'Artois et de Bourgoingne palatin, seigneur de Salins et de Malines.

A noz amez et feaulx conselliers, le sire de la Chapelle, messire Monfrant d'Essines et messire Jaques Belle, chevaliers, Robert de Capples, nostre bailli de Bruges, Andrieu de Douay, nostre recheveur general de Flandres et d'Artois, David Bousse, maistre de noz comptes a Lille, Danckaert de Ogierlande, nostre bailli de Gant, Jehan de Latre, nostre bailli d'Alost et Jehan le Chien, chastellein, bailli et receveur de Bevere, saluut et dilection.

Ja soit ce que par noz autres lettres patentes et pour les causes declarees en ycelles, nous vous eussions commiz 
et ordonné de vous transporter et assembler en lieu convenable, tel que vous aviseries et bon vous sembleroit, et de illecq appellez avecques vous noz bien amez Victor de la Faucille, Lievin Papal, messire Bauduin le Vos, chevalier, sire de Pollar, Lievin le Scotelare, le sire de Boosinghe, Andrieu Paldinc le viel, Gille de Kercstede le viel et Guillamme de Messein, deputez de par noz bonnez villes Gant, Bruges, Ypre et de nostre terrouer du Franc, de par bon avis et meure deliberacion faire l'ordonnance et imposer sur chascune de noz villes, chastellenies et terrouers de nostre pays de Flandres selon l'estat et faculté de chascune d'icelles sa part et porcion, telle que vous sembleroit de raison, l'aide et subvencion de la somme de cent huit mille doubble escuz de nostre forge et nouvelle monnoie de Flandres, a nous consenti et ottroié ceste fois par nostre dit pays de Flandres tant pour et a cause de nostre joyeux avennement et premiere entree en ycellui nostre pays et pour nous aidier a supporter les grans charges, qui nous sont survenues et avons eu a soustenir pour le fait de la commune marchandise d'entre nostre dit pays de Flandres et cellui d'Engleterre comme autrement, ensemble les autres frais apparans, qui sont a lever pour le bien commun de nostre dit pays. Et que nostre entencion estoit lors de vous avoir ordonné et commiz comme dessus de avecq ce, que dit est, asseoir soubz umbre des mos des dis frais apparans entre autres parties la somme de $X^{m}$ doubles escuz, telz que dit est dessus, sur nostre dit pays de Flandres, excepté les dis quatre membres, pour les frais et despens, que yceulx quatre membres ont fait et soustenus depuis seize ans en ça a poursievir le dit fait de la dite marchandise tant au dit pays d'Engleterre comme autrement. Neantmoins soubz umbre de ce que il y a autre frais a assenir pour cause de la vaquacion de l'imposicion de l'ayde et subvencion dessusdite, vous avez differé et encores differez 
de asseoir yceulx $\mathrm{XX}^{\mathrm{m}}$ doubles escuz, sans sur ce avoir autre mandement de nous, sicomme entendu avons. Pour quoy nous, ces choses considerees, et qui voulons la dite assiete des dis $\mathrm{XX}^{\mathrm{m}}$ doubbles escuz estre assiz et imposez ceste fois en la maniere dessus touchié au proffit des diz quatre membres, sans ce qu'il soit tant ou tamps avenir a consequence au proufit de nos diz quatre membres ne porte aucun prejudice a nous ou a nostre seignourie ne a noz ditez autres villes, chastellenies et terroners de nostre dit pays, sur les autres villes, chastellenies et terrours d'icellui selon l'estat et faculté d'icelles, en baillant lettres de la dite assiete ycelle faite telles et a ceulx qu'il appartendra, se mestiers est, vous mandons, commandons et estroitement enjoingnons par ces presentes, que, avant que vous partez du lieu d'Oudembuerch, ou vous estes encores assemblez pour la dite imposicion et assiete faite de la subvencion dessusdite et frais dessus touchiés, vous par bon avis et meure deliberacion appelez avecques vous les deputez dessus nommés, assees et imposees au proufit des diz quatre membres de nostre dit pays et par les condicions devantdites sur les autres villes, chastellenies et terrours d'icellui selon l'estat et faculté de chascune d'icelles et non selon le transport par la fourme et maniere, que vous aviseres qu'il sera a faire, pour le mieulx de ce faire, donnons povoir, auctorité et mandement especial a vous, aux huit ou sept de vous, mandons et commandons a tous noz justiciers, officiers et subges et autres a qui ce puet touchier, que a nous et a vous, commiz en se faisant, obeissent et entendent diligaument. Car ainsi nous plaist il et le volons estre fait, non obstant que en noz dites autres lettres ne est faite expresse mencion des dis $\mathrm{XX}^{\mathrm{m}}$ escuz ne de l'assiete d'iceulx ordonnances, mandemens ou deffenses a ce contraires.

Donné en nostre ville de Courtray, le derenier jour d'aoust, l'an de gracc mil rCCC et huit. 
[Get.] Par monseigneur le duc vous present, G. de la Boede.

De burgemeesters, schepenen en raad van de stad Brugge belasten Boudewijn de Vos en Lieven de Scuetelare ermede als gedeputeerden Brugge te vertegenwoordigen op de vergaderingen te Oudenburg, waar een nieuwe repartitiebasis zal opgesteld worden voor de bede van 108.000 dubbele schilden: hernieuwing van deze volmacht door het nieuwe stadsbestuur.

Brugge, 2 september 1408 .

$A$. Origineel. Niet voorhanden.

$B^{1}$. AFSCHRIFT van 9 september $\mathrm{I}_{4} 08$; als $\S 5$ van de enquêterol van $\mathrm{I}_{4} \mathrm{O} 8$, ekspeditie voor het Brugse Vrije (uitgegeven als tekst 5) ; naar A. - B. RA, Charters van het Brugse Vrije, nr. 279.

$\left(B^{2}-B^{3}-B^{4}-B^{5}\right.$. Afschriften) Zie 1, ibidem.

$C^{2}$. Afschrift, s. XV in., in de Ouden Wittenbouck van de stad Brugge, fo I $50 \mathrm{v}$; naar $B^{2}$.-Stadsarchief van Brugge. $D^{2}$. Afschrift, s. XV ex., in de Groenen Bouck $B$ van de stad Brugge, fo $29 \mathrm{I}$; naar $B^{2}$.-Stadsarchief van Brugge.

$C^{3}$. Afschrift Zie I, $C^{3}$.

Uitgave: F. Priem-O. Delepierre, Précis analytique, dl. VI, pp. I 5 I-I 53 .

Vermelding: L. Gilliodis-van Severen, Inventaive, dl. IV, p. 23.

Allen den ghonen, die dese lettren zullen zien iof horen lesen ende zonderlinghe edelen ende werden den commissarisen ons gheduchs heeren ende princhen, ons heeren shertoghe van Bourgoingnen, grave van Vlaendren ende den ghedeputeirden van den steden van Ghend, Ypre ende van den lande van den Vryen als over de drie leden van den zelven lande van Vlaendren, nu vergadert wesende tOudembuerch, omme te ordonneirne, hoe ende 
in wat manieren onse voorseide gheduchte heere ende prinche zal doen upheffen ende ontfaen de hulpe, hem ghedaen ende gheconsenteirt nu onlanxleden bi zinen ghemeenen lande voorseit, ende de costen, die de voorseide commissarisen ons gheduchs heeren ende de ghedeputeirde van den vier leden van den lande ghedaen zullen hebben den tijt, dat zij ten voorseiden sticke zullen hebben verstaen, ende al dierghelike omme te stelne ende te ordineirne de twintich dusentich dobbele scilden, die de smalle stede ende castelrien van den lande van Vlaendren sculdich zijn up te rechtene ende weder te keerne den viere leden van den lande voorseit als over de costen, die de voorseide lede ghehadt hebben zestien jaer lang in zendeboden ende andersins omme torbaer ende proffijt van den ghemeenen lande, buerchmeesters, scepenen ende raed van der stede van Brucghe, waerdichede ende alle vrienscepe.

Ute dien clat de goede lieden van der wet, die onlanxleden tregement hadden van der voorseider stede van Brucghe van ons voorseits gheduchs heeren weghe, ghestelt ende ghedeputeirt hadden mer Boudine den Vos, ridder, heere van Pollare, ende I,ievine den Scuetelare, omme in den name ende over de stede van Brucghe te verstane ten sticken voorseit, nu verlaten zijn ende de voorseide wet vernieut, also het heift ghelieft onsen voorseiden gheduchten heere. Ende mids dien de voorseide mer Boudin de Vos ende Lievin de Scuetelare hemlieden niet zouden durven noch willen bewinden van den voorseiden sticken zonder speciale macht ende bevel daeraf van ons te hebbene, so eist dat wij, omme te vulcommene de begheerte van onsen voorseiden gheduchten heere ende te verhoedene, dat bi onsen ghebreke de zaken ende sticken voorscreven niet verachtert en werden ofte belet in eenigher manieren, betrauwende te vullen in de goede wijsheit, ghetrauwicheit ende neerensticheit 
van den voorseiden mer Boudine den Vos ende Lievine den Scuetelare, hebben dezelve personen ende elken zonderlinghe ghecommitteirt, ghestelt ende gheordineirt ende bi desen lettren committeren, stellen ende ordineren, omme metsgaders hulieden, die commissarise zijt van ons gheduchs heeren ende princhen weghe, ende den ghedeputerden van den voorseiden stede Ghend, Ypre ende lande van den Vryen te ordineirne, hoe ende in wat manieren men dese waerven de voorseide hulpe, onsen gheduchten heere gheconsenteirt, de costen van den commissarisen ende ghedeputeirden metsgaders den twintich dusentich dobble scilden voorseit, betalen sal, hem beeden ende elken zonderlinghe daerof ende van al, datter ancleven zal, vulle macht ghevendc cndc spcciale bevel ende omme elken van den steden ende jeghenoden van den lande van Vlaendren dese waerven zonder meer hare porcie ende tax deraf te stelne ende te ordineirne ten rechtvaerdelixsten, dat men sal connen ende moghen, ende generalike al derin te doene dat wij zelve doen zoude moghen, bialso dat wij present ende voor oghen waren, belovende bi trauwen ende eeren, dat goet ende ghestade te houdene ende daerjeghen niet te doene of te gane in eenigher wijs.

Ghegheven in kennessen der waerheden onder den zeghel van zaken van der voorseider stede van Brucghe upten andren dach van septembre int jaer ons Heeren M CCCC ende achte.

[Get.] Julien.

De schepenen en de raad van de stad Gent belasten Victor van der Zickele en Lieven Papal ermede als gedeputeerden Gent te vertegenwoordigen op de vergaderingen te Oudenbury, 
waar een nieuwe repartitiebasis zal worden opgesteld voor de bede van 108.000 dubbele schilden: hernieuwing van deze volmaiht door het nieure stadsbestuur.

$$
\text { Gent, } 5 \text { september } 1408 \text {. }
$$

$A$. Origineel. Niet voorhanden.

$B^{1}$. Afschrift van 9 september 1408 ; als $\S 4$ van de enquêterol van I 408, ekspeditie voor het Brugse Vrije (uitgegeven als tekst 5) ; naar A.-B. RA, Charters van het Brugse Vrije, nr., 279.

$\left(B^{2}-B^{3}-B^{4}-B^{5}\right.$. Afschriften). Zie 1, ibidem.

$C^{2}$. Afschrift, s. XV in., in de Ouden Wittenbouck van de stad Brugge, fo 150 ; naar $B^{2}$. - Stadsarchief van Brugge. $-D^{2}$. Afschrift s. XV ex., in de Groenen Bouck B van de stad Brugge, fo $290 \mathrm{v}$; naar $B^{2}$. - Stadsarchief van Brugge.

$C^{3}$. Afschrift. Zie 1, $C^{3}$.

Uitgave: F. Priem-O. Delepierre, Précis analytique, dl. VI, Pp. I48-I5O.

Vermelding: I. Gilliodts-van Severen, Inventaire, dl. IV, p. 22.

Allen den ghuenen, die dese presente lettre zullen zien ofte horen lesen ende zonderlinghe edelen ende werden den commissarisen ons gheduchs heeren ende princhen, ons heeren shertoghe van Bourgoingnen, grave van Vlaendren, ende den ghedeputeirden van den steden Brucghe, Ypre ende van den lande van den Vryen als over de drie lede van den zelven lande van Vlaendren, nu wesende vergadert te Audembuerch, omme te ordonneirne, hoe ende in zo wat manieren onse voorseide gheduchs heere ende prinche sal doen upheffen ende ontfaen de hulpe, hem ghedaen ende gheconsenteirt nu onlanxleden bi zinen ghemeenen lande voorseit, ende de coste die de voorseide commissarise ons gheduchs heeren ende ghedeputeirde van den vier leden van den lande ghedaen zullen hebben den tijt, dat zij ten voorseiden sticke zullen 
verstaen hebben, ende al diesghelike omme te stellene ende te ordonneirne de $\mathrm{XX}^{\mathrm{m}}$ dobble scilden, die de smale steden ende castelrien van den lande van Vlaendren sculdich zijn up te rechtene ende weder te keerne den vier leden van den lande voorseit als over de costen, die de voorseide lede ghehad hebben zestien jaer lang in sendene boden of andersins omme torboor ende proffijt van den ghemeenen lande, scepenen ende raed van der stede van Ghend, werdichede ende alle vrienscepe.

Ute dien dat de goede lieden van der wet, die onlanxleden tregement hadden van der voorseider stede van Ghent beede van ons gheduchs heeren weghe ende der voorseider steden weghe van Ghent, ghestelt ende ghedeputeirt hadden Victore van der Zickele ende Lievine Papael, omme in de name ende over de voorseide stede van Ghent te verstane ten zaken voorseit, nu verlaten zijn ende de voorseide wet vernieut, also het van auden tiden ghecostumert es. Ende mids dien de voorseide Victor ende Lievin hemlieden niet zouden durven noch willen bewinden van den voorseiden sticken zonder speciale macht ende bevel van ons te hebbene, so eist dat wij, omme te vulcommene de begheerte van onsen voorseiden gheduchten heere ende te verhoedene dat bi onsen ghebreke de zaken ende sticken voorscreven niet verachtert en worden of belet in eenigher manieren, betrauwende te vullen in de goede wijsheit ende ghetrauwicheit van den voorseiden Victore ende Lievine, hebben dezelve personen ende elken bizondre ghecommitteirt, ghestelt ende gheordonnert ende bi desen lettren stellen, committeren ende ordineren, omme metgaders huleden, die commissarise zijt van ons voorseits gheduchs hecren ende princhen wcghe, ende den ghedeputcirden van den voorseiden steden Brucghe, Ypre ende lande van den Vryen te ordinerne, hoe ende in wat manieren men dese waerven de voorseide hulpe, onsen gheduchten 
heere gheconsenteirt, de costen van den commissarisen ende ghedeputeirden metgaders den $\mathrm{XX}^{\mathrm{m}}$ dobble scilden voorseit betalen sal, hem beeden ende elken zonderlinghe deraf ende van al, datter ancleven mach, vulle macht ghevende ende speciael bevel ende omme elken van den steden ende jeghenooden van den lande van Vlaendren dese waerven zonder meer hare portie ende tax deraf te stelne ende te ordineirne ten rechtvaerdelixsten, dat men sal connen ende moghen, ende generalike al derin te doene, dat wij zelve doen zouden moghen, bialso dat wij present ende voor oghen waren, belovende bi trauwe ende bi eeren dat goet ende ghestade te houdene ende derjeghen niet te doene of te gane in eenigher wijs.

Ghegheven in kennessen der waerheden onder den zeghel van zaken der voorseider stede van Ghent upten vijfsten dach in septembre int jaer XIIII' ende achte. [Get.] Everwijn.

Herziening van de repartitiebasis van de beden ter gelegenheid van de heffing van de bede van 108.000 dubbele schilden, door de Vier Leden van Vlaanderen toegestaan bij de blijde inkomst van Jan zonder Vrees in Vlaanderen als graaf. Deze nieuwe repartitie zal die van het "oude" Transport vervangen, tenminste voor wat betreft de verdeling van de beden. Deze herziening gebeurt te Oudenburg door 9 kommissarissen van de hertog en door 8 gedeputeerden van de Vier Leden, voor elk Lid twee.

Oudenburg, 9 september I 408 .

$A^{1}$. Origineel. Ekspeditie bestemd voor het Brugse Vrije. Perkamenten rol, samengesteld uit 7 bladen, met een gezamenlijke lengte van $3290 \mathrm{~mm}+$ plica $75 \mathrm{~mm}$ en een breedte 
van $445 \mathrm{~mm}$. De bladen hebben een ongelijke lengte : blad I : 520; blad 2: I60; blad 3:500; blad 4:620; blad 5 \& 6 : elk 6ro; blad $7: 270+$ plica : 75. Blad I en 2 zijn rechts licht beschadigd. De bladen zijn aaneengenaaid met koorden, uit perkament vervaardigd, waarvan de uiteinden aan de linkse zijde uitsteken en telkens verzegeld zijn met een klein rood wassen zegel (één bewaard). Onderaan de rol hingen aan dubbele perkamenten staarten oorspronkelijk i 7 kleine zegels (van de kommissarissen en gedeputeerden); hiervan zijn er I4 staarten bewaard en 8 zegels, allen min of meer beschadigd waarvan 7 in rode was en $I$ in zwarte was.

Op de rug (blad 7) : 1) Gelijktijdige hand : "V[oor] Vrye De veranderinghe van de smaeldeelinghen in Vlaendren $\left(^{a}\right)$, ghemaect tOudenb[uerch] $a^{o} \mathrm{XIII}^{c}$ achte zonder verminderinghe of preiuditie van den ouden transporte $n-2) \mathrm{s}$. XVIII : "I $408-\mathrm{N}^{\circ} 3\left(^{(b)}-\mathrm{C}^{t a}\left({ }^{b}\right)\right.$ I8 $\left({ }^{c}\right)$ ".

B. RA, Charters van het Brugse Vrije, nr. 279.

$\left[A^{2}\right.$. Origineel. Ekspeditie bestemd voor de stad Brugge. Niet voorhanden.]

[ $A^{3}$. Origineel. Ekspeditie bestemd voor de Rekenkamer van Rijsel. Niet voorhanden.]

$\left[A^{4}\right.$. Origineel. Ekspeditie bestemd voor de stad Gent. Niet voorhanden.]

$\left[A^{5}\right.$. Origineel. Ekspeditie bestemd voor de stad Ieper. Niet voorhanden.]

$B^{1}$. AFSCHRIFT, s. XV m., in een papieren register (20 fo) met als titel : "Den transpoort van Vlaendren vernieud int jaer VIII ", fo I-I 4V ; naar $A^{2}$, maar zonder de kommissieoorkonden van Brugge en Gent. - B. RA, Registers van het Brugse Vrije, nr. 587 .

$B^{2}$. Afschrift, s. XV in., in de Ouden Wittenbouck van de stad Brugge, fo I49-I55 (nieuwe fo I62-I68) ; naar $A^{2}$. - Stadsarchief van Brugge. $-C^{2}$. Afschrift, s. XV ex., in de Groenen Bouck $B$ van de stad Brugge, fo $289-297 v$ (nieuwe fo $305-3$ r $3 v$ ) ; naar $A^{2}$-Stadsarchief van Brugge.

(a) Smaeldeelinghen in Vlaendren boven de regel geschreven, boven transpoorte, doorstreept. - $\left(^{b}\right)$ Gevolgd door 20 , doorstreept. - $\left(^{c}\right)$ Gevolgd door een onleesbare stempel. 
$B^{3}$. Afschrift, s. XV, in een reeks losse dokumenten, achteraf samen ingebonden; katern 8 ; naar $A^{3}$. - A.D.N., série $B$, nr. 19.482 .

Uitgaven : a) F. Priem-O. Delepierre, Précis analytique des documents que renferme le dépôt des Archives de la Flandre Occidentale à Bruges. II e série., 9 dln., Brugge, I843-I858; dl. VI, pp. I39-I82 (I). - b) L. Gilliodts-van Severen, Inventaire des archives de la ville de Bruges. Section première. Inventaire des chartes. I e série: $X I I-X V \mathbf{e}$ siècles., 9 dln., Brugge, I87I-I885; dl. IV, pp. I9-30 (partiëel, naar $B^{2}$ ).

Vermeldingen : a) s. XV, Witte Bouck van de stad Gent (G. SA, serie 93bis, nr. I), fo r63v. - b) s. XV m., Transportregister van de stad Gent (G. SA, serie 93bis, nr. 5), fo 9v. c) s. XV in., Transportregister van de Rekenkamer (A. RA., Rekenkamer, nr. I244), fo I.

\section{Blad 1, 1}

Dit es dordonnanche, hoe dat men dese waerften ommezetten ende betalen zal de subvencien van hondert achte duust dobbelen scilden van XLVIII groten tstic nieuwer munten van Vlaendren, maken $I^{\mathrm{c}} L I \mathrm{X}^{\mathrm{m}}$ ende II ${ }^{c}$ lb. par. der voorseider munte, ghewillecuert ende gheacordeirt up desen tijt minen heere den hertoghe van Bourgoingen, grave van Vlaendren, van Artois, van Bourgoingen, bi zinen ghemeenen lande van Vlaendren voorseit omme de cause van zijnre blidre toecomste ende eerst incommen van zinen voorseiden lande van Vlaendren, ende omme hem te helpen draghen de grote lasten, die hem zident overcommen zijn, heift ghehadt ende moeten draghen omme de ghemeene coopmanscipe tusschen zinen voorseiden lande van Vlaendren ende dien van Ingheland ende anders in menigher manieren, omme die te

(I) Deze uitgave is helemaal niet-kritisch. De uitgever heeft op eigen gezag niet-gefundeerde tekstwijzigingen aangebracht en bovendien blijkbaar een aantal passus verkeerd gelezen of geïnterpreteerd. 
heffene ende te doen ontfane tsinen proffite up de steden, landen ende castellerien van den voorseiden lande van Vlaendren na state ende goede ende niet up dordonnance van der erveliker rente, gheheeten toude transpoort van Vlaendren, up dewelke men in tiden verleden ende specialike voor de laetste beroerte binnen den voorseiden lande men plach omme te zettene alle subvencien, beden, commeren ende lasten, commende up tvoorseide land, up alle de stede, landen ende castelrien derbinnen zijnde, telken alst te doene was ende den lande voorseit eenich last overquam, twelke nu niet wesen mach omme de causen ende redenen hierna verclaerst. Ende dewelke ordonnance ghemaect ende gheordonneirt es in de stede van Oudenbuerch zonder preiudicie van der voorseider renten van den houden transporte van Vlaendren noch die te nopene te minderne of te meersene ter bate, scade of achterdeele van minen voorseiden heere of andren, maer die blivende in zulken state ende werden als zij was ende stond voor dese voorseide ordonnance bi den commissarisen van minen voorseiden heere ende den ghedeputeirden van den vier leden van Vlaendren, hierna ghenoomt, daer vergadert omme de voorseide zaken te doene ende te vulcommene ten besten ende ten meesten besceede naer haerre macht ende wetenthede ende den inhoudene van der hopenre commissie van minen voorseiden heere, hiernaer voor dverclaerst van der voorseider ordonnance inghescreven van woorde te woorde.

\section{$\S 2$}

Ende es te wetene dat de costen van den IX commissarisen van minen voorseiden heere bi taxacien van minen heere den canchelier ende van mijns voorseits heeren rade ende ooc de costen van den [VIII] $\left({ }^{a}\right)$ ghedeputeirden

(a) Onleesbaar door beschadiging; hersteld aan de hand van $B^{1}$. 
van den voorseiden viere leden van den lande van Vlaendren voorseit, hierna ghenoomt in de voorseide commissie van minen voorseiden heere, die ten voorseiden zaken ende omme dese voorseide ordonna[n]ce [te] $\left({ }^{a}\right)$ makene ende die te zettene in ordene ende in der manieren hiernaer verclaerst, hebben verstaen eempaerlike eer zijt hebben gheconnen vulbringhen ter voorseider stede van Oudembuerch ende anders XXXV daghen lanc hendende den IXten dach van septembre M.CCCC ende achte, elc ruddre ten prise van IIII vranken sdaechs ende elc van den andren te III vranken [sdaechs] $\left({ }^{a}\right)$, ende voort omme de costen van vele messagerien ende boden, uteghesent omme de cause ende voordringhe van den voorseiden zaken ende ooc omme de costen van vele notablen [lieden], ouder[linghen] (a) ende meest kennesse hebbende van den jeghenoden, landen ende contreyen van den landen ende castellerien van Vlaendren voorseit in allen ziden also wel dienaers van minen voorseiden heere als [andere] (a), omboden bi den voorseiden commissarisen bi hemlieden te commene, omme te wetene dordonnance, hoe zij omme plaghen te zettene elc in zine castelrie de rente van den voorseiden ouden transpoorte [van] ( $\left.{ }^{a}\right)$ Vlaendren ende voort hem last te ghevene te besoukene de verloren landen ende contreyen bi der vloet van der zee ende int ghelike bi den zande van den dunen ende anders, ende den [voorseiden] ( $\left.{ }^{a}\right)$ commissarisen ende ghedeputeirden over te bringhene in ghescriften tghuend, dat zij daerof bevonden zouden hebben also zij wel ghedaen ende vulcommen hebben, omme daerup, die overghe$\mathrm{s}$ [ien] $\left({ }^{a}\right)$ ende thinhouden van dien gheweten, voort te ghane in dese voorseide ordonnance te makene ten meesten besceede ende daerup te ordonneirne in der manieren, dat behoren zoude naer rechte ende [naer] (a) redenen ende

(a) Onleesbaar door beschadiging; hersteld aan de hand van $B^{\mathbf{1}}$. 
den inhoudene van der voorseider commissie, ende omme den cost van den scrifturen, daertoe ende te desen voorseiden zaken dienende, te makene ende stoffen daertoe te leverne ende ooc alle andre smalle costen, in dese zaken overcommen, belopende alle te gadre in sommen, alsoot bleken es den voorseiden commissarisen ende ghedeputeirden bi den paertijen bi hemlieden overghesien, ghetaxeert, gheworpen ende gheexamineirt ende dewelke costen boven ende met der voorseider sommen van CVIII $^{m}$ dobble scilden voorseit zijn omme te zettene na [dese] ( $\left.{ }^{a}\right)$ voorseide ordonnance up de steden, landen ende castelrien hierna verclaerst, omme dat zij ghedaen zijn ter bate, orboore ende proffite van den ghemeenen lande van Vlaendren $\mathrm{sp}[\mathrm{r}] \mathrm{ut}[\mathrm{ende}]\left({ }^{a}\right)$ uter causen van deser voorseiden subvencien, IIIm IIIIc $X$ lb. par. der voorseider munten van Vlaendren. Ende daertoe sal men noch ommezetten na dese ordonnance up de smale steden ende caste[lrien] ( $\left.{ }^{a}\right)$ van Vlaendren hiernaer verclaerst noch $\mathrm{XX}^{\mathrm{m}}$ dobblen scilden ende niet up de viere leden voorseit omme de causen ende redenen verclaerst hierna int hende van deser voorseider navolghender ordonnance.

$\S 3$

Hierna voolcht thinhouden van der voorseider commissie van minen voorseiden heere (I).

Aldus gheteekent : (2).

Up den ricghe van welker lettre stont ghescreven, tgond dat hiernaer volcht: (3).

(a) Onleesbaar door beschadiging; hersteld aan de hand van $B^{1}$.

(I) Hier volgt de kommissie-oorkonde van Jan zonder Vrees van 20 juli I 408 . Zie tekst 1.

(2) Zie de laatste alinea van tekst 1.

(3) Zie traditie $A$ van tekst 1 . 
$\S 4$

Tinhouden van eenre openre lettre van der stede van Ghent anegaende de voorseide zaken es zulc als hiernaer volghet van woorde te woorde.

\section{Blad 2 (I)}

Aldus gheteekent : (2)

\section{blad $3, \S 5$}

Hierna volghet thinhouden van eenre andre openre lettre van der stede van Brucghe aengaende de voorseide saken als boven (3).

Aldus gheteekent : (4).

$\S 6$

Ende es te wetene dat hier ne gheene lettren van der stede van Ypre ende lande van den Vryen inghescreven staen, omme dat tscependom ende macht van haren ghedeputeirden voorseit niet uutghinc noch expireirde bin der tijt, dat men over dese zaken onledich was, alsoot dede van den voorseiden ghedeputeirden van Ghend ende van Brucghe, ne hadden zij niet bi den voorseiden tween laetsten lettren, hiervoren inghescreven, weder gheweist, machtich ghemaect bi den nieuwen scepenen na hemlieden in der manieren, dat daertoe behoorde ende in de voorseide twee lettren verclaerst es.

(I) Hier volgt de kommissie-oorkonde van de stad Gent van 5 september I 408. Zie tekst 4.

(2) Zie de laatste alinea van tekst 4.

(3) Hier volgt de kommissie-oorkonde van de stad Brugge van 2 september I 408. Zie tekst 3.

(4) Zie de laatste alinea van tekst 3. 


\section{$\S 7$}

Eerst up de steden ende paertijen, die al verdronken zijn van der zee ende verloren teeuwighen daghen zonder die weder te vercrighene in toecommenden tiden.

Primo, de stede van Lancardenbuerch, die plach te gheldene in de voorseide rente van den voorseiden transpoorte XXVI s. ende VIII d., dat quam up thondert IIII d., ne sal niet betalen bi deser ordonnance in dese voorseide subvencie, omme dat zij verdronken ende verloren es van der zee, also voorseit es.

Item, Roeselare bi Ardenbuerch, dat plach te gheldene int voorseide transpoort LIII s. III d., dat quam up thondert VIII d., ne sal niet betalen als boven.

Item, Waterdunen, dat plach te gheldene in transpoorte IIII lb., quam up thondert XII d., ne sal niet betalen als boven.

Item, de stede van Ysendike, die plach te gheldene in transpoort voorseit LIII s. IIII d., quam up thondert VIII d., ne sal niet betalen als boven.

Ende de stede van Hughevliete, die plach te gheldene in transpoorte voorseit XX s., quam up thondert III d., ne sal niet betalen als boven.

Item, andre steden, landen ende castelrien, daeraf eenighe partien verloren zijn ende verdronken van der zee ende andre verloren ende vervloghen van den zande van den dunen ende ooc anders, zijn veraremt ende verweect in der manieren hierna volghende.

Primo, tland van den Vryen, dat ghelt in tvoorseide houde transpoort MLXVII lb., comt up thondert XIII lb. VI s. IX d., int welke land zijn vele ambachten, prochien ende jeghenooden ende onder dandre dambochten hiernaer volghende.

Eerst tambocht van Ysendike, groot neghene prochien, daer inbegrepen waren XXVIIIm ghemeten lands, twelke 
ambacht plach te betaelne also eenighen zecghen den $\mathrm{X}^{\text {sten }}$ penningh van allen lasten van den voorseiden lande van den Vryen, maer nu ten tijt eist al verdronken van der zee zonder de tweedeel van eenre van den voorseiden neghene prochien, gheheeten Gaternesse, draghende de voorseide tweedeel XIcXXX ghemeten lands, dat commen zoude den XIIIIsten penningh up thondert van der somme van den voorseiden transpoorte, twelke niet jeghenstaende es gheaviseirt bi den commissarisen voorseit omme zekere zaken, hem daertoe porrende, dat men tvoorseide verlies dien van den voorseiden lande van den Vryen afcorten ende minderen zoude ten avenante van den XVIIIsten d. Ende voort es te kennesse commen als boven dat eene jeghenoode, gheheeten Helmare, ende noch een andre, gheheeten Botersam, gheleghen int voorseide ambacht, die niet begrepen zijn int voorseide verlies ende minderinghe, voren verclaerst, al eist dat zij waren begrepen int voorseide ambocht ende ooc al verloren ende verdronken zijn van der zee als boven. Dewelke verliese al overghesien, het es gheoordonneirt dat men hier ten avenante van der voorseider somme van den voorseiden transpoorte afcorten sal ende rekenen verloren ten eeuwighen daghen, up elke hondert pond voor al tvoorseit verlies : XIX s. IX d.

Item, Oostbuerch ambocht int voorseide land van den Vryen, dat plach te bevane, metsgaders Wulpen dat betaelde metten voorseiden ambochte, XVIImVIcLXXVII ghemeten lands ende te betaelne den XIIIsten penningh van allen lasten van den voorseiden larıde van den Vryen, alsoot bilix bevonden es, maer niet up tjuste. Ende nu ter tijt zijn daerin verdronken van der zee ende niet weder te vercrighene als boven IIImIXc ghemeten lands; aldus zouder bleven zijn in state XIIImVIIcLXXVII ghemeten lands, maer omme eenighe zaken, daertoe porrende de voorseide commissarise, es dblivende 
land voorseit ghesommeirt te XIIIImVIcLXXVII ghemeten lands. Ende voort omme dat bevonden es dat tvoorseide ambocht ne plach te betaelne ne waer den XXIIIIsten d., also eenighe secghen, van den lasten van den voorseiden lande van den Vryen, so es gheordonneirt als boven, dat men minken zal ende rekenen verloren teewighen daghen, up elke hondert pond voor al tverlies int voorseide ambocht als boven, II s. III $d$.

Item, Ardenbuerch ambocht int voorseide land van den Vryen, dat plach te betaelne, also men seicht, den XVIIIsten $d$. van den lande van den Vryen, daeraf die van Casant plaghen te betaelne den derden penningh, also men seicht, die van Bewester Ee van den zeven penninghen, diere overbleven, de drie, ende dander viere penninghe, die der overbleven, plaghen te betaelne die van Beooster Ee; dewelke van Beooster Ee verloren hebben van der vloet van der zee ende in dicagen ende anders C.X ghemeten lands, ende daertoe in vive inzeten ende metter havene van Koczide noch verloren als boven $\mathrm{XC}$ ghemeten lands, die niet weder te vercrighene zijn als boven. Ende alle zaken overghemerct ende de verweecthede van den voorseiden ambochte in andren manieren bi toedoene van der voorseider zee, het es gheordonneirt dat men minken zal ende rekenen verloren teewighen daghen over al tverlies van Casant ende sine toebehoorte ende andre verliesen van Beooster $\mathrm{Ee}$ voren verclaerst, als boven II s. VI d.

\section{Blad 4}

Item, hierboven zijn verloren ende vervloghen binnen den lande van den Vryen van den zande van den dunen ende verdijct an de zeezide tusschen der sluus van Reingaertsvliete ende Camerlinx ambocht ende dat mede der inbegrepen de partien van lande hiernaer volghende ende die niet weder te vercrighene zijn als boven, dats 
te wetene vervloghen van den dunen in de wateringhe van Volkaerts Ghote beoosten Sinte Kateline ten Cnocke omtrent VIII ghemeten lands ende ooc een groot doorp derbi staende, yet $\left({ }^{a}\right)$ ten Vijfhuuse, es al te nieten zonder twee cleene woensten. Item, van Sinte Katelinen ten Cnocke voorseit van der wateringhe van Volkaerts Ghoote treckende westwaerd toter wateringhe van Heys ende in de wateringhe van Reingaertsvliete es ooc verloren bi der vloghe van den zande van den dunen $\mathrm{C}$ ghemeten lands int welke gherec stond een doorp, yet $\left({ }^{a}\right)$ Staerte $\left({ }^{b}\right)$, daer vele lieden woende, neeringhe ter zee doende, die nu al te nieten zijn.

Item, voort van der wateringhe van Reingaertsvliete in de wateringhe van Heys, streckende tote den doorpe van Heys, zijn verloren eene jeghenoode, gheheeten De Panne, die al vervloghen ende te nieuten es bi den dunen omtrent LXXX ghemeten lands ende dit verlies es in Lisseweghe ambocht. Item, van den doorpe van Heys westwaert streckende toter wateringhe van Blankenberghe es verloren bi nieuwen zeediken ghemaect omtrent II ${ }^{c}$ ghemeten lands ende es int voorseide ambocht van Lisseweghe ende van Huutkerke. Item, in de wateringhe van Blankenberghe van der sluus van der voorseider wateringhe streckende westwaert tote den doorpe van Wendunen, es verloren van nieuwen zeediken ende bi den vloghen van den dunen omtrent LXXX ghemeten lands ende hierin stond een groot doorp, gheheeten Harendike, daer lettele yement woend. Item, van danen westwaert duer tdoorp van Wendunen streckende tote jeghen de muelne ten Bleckaerde es verloren bi der vloghen van den dunen $\mathrm{L}$ ghemeten lands. Ende dese twee percheelen zijn al int ambocht van Huutkerke. Item, van

(a) Sic ; betekent heette. - ( $\left.{ }^{b}\right)$ Strate, $B^{1}$. 
der voorseider muelne westwaert streckende tote eene jeghenoode, heet Vogheldike, es verloren bi vloghen van den dunen omtrent XX ghemeten lands. Item, van danen westwaert streckende toter zidelinghe, commende an de wateringhe bi sheere Woutermans ambocht, twelke lanc es onderhalf mile of daerboven, es vervloghen ende verloren van den dunen van eenen zande, gheheeten Tolin zant in Vlissegheem, twelke alle jare breet omtrent $\mathrm{XV}^{\mathrm{c}}$ ghemeten lands. Ende hierin stonden scone doorpen, die alle te nieuten zijn. Ende dit voorseit gherec leicht in Vlissegheem, in Clemskerke ende in Breedenee houc ende in sheer Woutermans ambocht. Van Oosthende westwaert tote Camerlinx ambocht zijn verloren in dicagen IIIc ghemeten lands. Ende van Oosthende oostwaert tote sVinx ambocht zijn vervloghen van den zande van den dunen VIc ghemeten lands. Maken in sommen dese voorseide partien van lande IImIXcXXXVIII ghemeten lands. Daervoren es gheminct ende gheordonneirt af te slane ende te rekene verloren up elke hondert pond over al als boven II s.

Item, den voorseiden lande van den Vryen noch afghecort ende ghemindert omme tverlies ende weechede van den Canonike laten van Sinte Donaes van Brucghe boven dat zij hebben in de verloren landen hiervoren te baten als boven XXVI d.

Ende aldus dese voorseide VI partien van verliese afghesleghen dien van den lande van den Vryen voorseit, draghende te gadre XXVIII s. VIII d. Zij bliven betalende van elken honderde in dese voorseide subvencie de somme van XI lb. XVIII s. I d.

Item, tland van den Viere Ambochten, dat ghetaxeert was in den voorseiden ouden transpoort IIcXLVI lb., comd up thondert III lb. XVIII d. Int welke land zijn viere ambochten in der manieren dat de name draecht, dats te wetene, Bochoutre ambocht, Ulstre ambocht, 
Asseneder ambocht ende Axele ambocht, dewelke zijn in partien verloren ende verweect in der manieren hiernaer verclaerst. Van denwelken taxe in orloghen ende subvencien ende niet in transpoorte, mids dat zij ne gheen ghelden, omme dat zij zijn van den keyserike, al waren zij derin ghetaxeert, de stede van Hulst betaelt tienste deel, dat loopt up thondert VI s. I d. hallinc poyteume $\left({ }^{a}\right)$ ende tvijfste deel van eenre poyteume. Aldus zouder bliven LV s. IIII d. ende tvijfste deel van eenen penninghe. Daeraf ghelden onder dandre Hulstre ambocht ende Axele ambocht metter poort van Axele deene helt ( $\left.{ }^{b}\right)$, comt XXVIII s. VIII d. ende tienste deel van eenen penninghe. Daeraf betalen Axele ende Axele ambocht van vijf penninghe de drie, comd XVI s. ende tvijfste deel van eenen pennijnghe, ende Hulstre ambocht van vive de twee, comd XI s. hallinc poyteume $\left({ }^{c}\right)$ ende twintichste deel van eenen pennijnghe. Ende Asseneder ende Bochoutre ambachten dander helt, draghende als boven XXVII s. VIII d. $\left({ }^{d}\right)$ ende tienste deel van eenen penninghe, daeraf Asseneder ambocht betaelt van viven de drie, comd XVI s., tvijfste deel van eenen penninghe ende de zes deelen van den tiensten deele van eenen penninghe, ende Bochoutre ambocht van den viven de twee, dat comd XI s., vier vijfste deele van eenen penninghe ende de viere deelen van den tiensten deele van eenen penninghe, die men deelt in Bochoutre ambocht in zeven besette. Ende zijn verloren in de ambachten voren verclaerst de partien hiernaer volghende.

Primo, in Hulstre ambocht in de prochie van Ossenesse, die houd XXXVc ghemeten lands ende galt tzesste deel van den voorseiden ambochte, dat comd XXII d., ende daer

(a) hallinc poyteume, $B^{2}$ en $C^{2}$; ob[ole], $\mathrm{p}^{\mathrm{o}}, A^{1}$ en $B^{1} .-\left(^{b}\right)$ Sic. - $\left(^{c}\right)$ hallinc poyteume, $B^{2}, C^{2} ;$ ob[ole] poyt [cume], $A^{1} . B^{1}$. - $\left.{ }^{d}\right)$ Sic. Volgens $B^{1}$ beide helften : XXVII s. VIII d. 
zijn in verloren $\mathrm{XXVIcXL}$ ghemeten lands, maken $\mathrm{XV}$ d. Aldus blijft er te betaelne int voorseide ambocht van elken honderden VII d., dewelke XXVIcXL ghemeten lands mueghen noch vercreghen ende bedijct werden. Item, Axele ambocht, dat ghelt also voren verclaerst es XVI s. ende tvijfste deel van eenen pennijnghe, zijn verloren in Ouden Otene van der zee, die niet weder te ghecrighene zijn, IIIcXXV ghemeten lands. Item, in Nieuwen Otene verloren LX ghemeten lands. Item, in den Noordpoolre verloren CXX ghemeten lands. Item, in Moermans polre CLXXXVIII ghemeten lands verloren ende in de prochie van Adendijc verloren bi der zee XII ${ }^{c_{-}}$ LXVI ghemeten lands. Maer van desen viere laetsten partien ne es niet verclaerst waneer noch in wat jaren dat zij verloren waren noch gheweten, of zij weder te ghecrighene zijn of niet. Ende nietmin het es gheordonneirt als boven, dat men hier minken ende afslaen zal voor dit voorseit verlies ende alle andre van den voorseiden viere ambochten gheheel boven den andren, verclaerst in de articlen van Hulstre ambocht hiervooren, Bochoutre ende Asseneder ambochten hierna, omme de verweecthede van den voorseiden viere ambochten, IIII s. up elke hondert pont. Aldus blijft er te betaelne int voorseide ambocht, ne ware dat eenighe van den andren drien ambachten bate of onbate hierof hadden dat te doene wart ende tondersceedene in de smalle deelinghen van den voorseiden viere ambochten; ende voort in elken bizondre van elken honderde in dese subvencie, XII s. ende tienste deel van eenen penninghe.

Item, in Assenedre ambocht, also men zeicht, ne es gheen verlies, anders dan verclaerst es int voorgaende article. Item, es te wetene dat int voorseide ambacht in de prochie van der Clusen de keerke van Eenam, mer Zegher van Ghend ende Symoen de Grutere hebben vele laten, die metten voorseiden ambachte dese waerf 
ghelden zullen in dese subvencien in der manieren, dat behoren ende redenen gheven sal.

Item, in Bochoutre ambocht, dat ghelt als boven verclaerst es XI s. IIII d. tvijfste deel van eenen penninghe ende de viere deelen van den tiensten deele van eenen penninghe, die men plach te betaelne up vier besette, dats te wetene de prochie van Wevelswale twee besette, Coudekerke een beset, Botersande, Vischersdoorp, Watervliet ende de Gheyns strate, die wilen lach bin der stede van Biervliet, een beset; welke viere besette voorseit bi der vloetganc van der zee verdronken ende verloren zijn uteghesteken een ghedeel van der Couder keerken, gheheeten de Laree, dat behouden es. De prochie van Bochoute ende tRiet tvijfste beset, van denwelken vijfste besette groot ghedeel verdronken ende verloren es. Ende over dat verlies es hem bleven te baten tbehouden land in Coudekerke, dat niet zo goet es als tgond dat verloren es; den mersch in $\left({ }^{a}\right)$ de prochie van Bassevelde tseste beset ende Oosteeclo, met dat daertoe behoort, tsevenste beset. Aldus comd tverlies van den voorseiden eersten viere besetten, verdronken ende verloren van der zee ende niet te ghecrighene in toecommende tiden, VI s. III d. Aldus blijftre, omme dandre drie besetten te betaelne int voorseide ambocht, van elken honderden in dese subvencien IIII s. IX d., viere vijfste deelen van eenen penninghe ende de viere deelen van den tiensten deele van eenen penninghe.

Ende aldus dese voorseide partien van verliese van al den voorseiden viere ambachten afghesleghen, draghende te gadre XI s. VI d. par., zij bliven betalende te gadre up elken hondert ponden in dese subvencie $\mathrm{I}$ s.

Item, tland van Waes, dat ghetaxeirt was ende ghelt in de rente van den voorseiden ouden transpoorte III $_{-}$

(a) in, $B^{1}, B^{2}, C^{2}, B^{3}$; in in, $A^{1}$. 
XIX lb. par., comt up thondert III lb. XIX s. IX d. Int welke land onder dandre prochien es eene gheheeten Melseele, die in de smale deelinghe van der sommen van der renten van den voorseiden ouden transpoorte betaelt alle jare $\mathrm{XX} \mathrm{lb.} \mathrm{In} \mathrm{dewelke} \mathrm{prochie} \mathrm{zijn} \mathrm{IIIm}$ II $^{c}$ ghemeten lands, die ten avenante van der voorseider somme alle betalen in de voorseide rente van den voorseiden transpoorte elke hondert ghemete XII s. VI d. par., die in de vergaderinghe maken de voorseide somme van XX lb. par. Maer daer zijn in de voorseide prochie verloren ende verdronken van der zee ende niet te vercrighene in toecommenden tiden $\mathrm{XV}^{c}$ ghemeten lands, die maken in sommen ten voorseiden prise ende zijnre in begrepen de $\mathrm{XL}$ s., dic mon jacrlix afslaet der voorseider prochie van Melseele als verloren in de rekeninghe van den ontfanghere van Vlaendren als van den voorseiden transpoorte IX lh. VI s. VIII d. up al den transpoort, comd up thondert II s. IIII d.

Item, den voorseiden lande van Waes, dat vele verlies heift als van den heere van Bevere, Calo, Verrebrouc, Kieldrecht ende andre, die met hemliedeı plaghen te betaelne up transpoort voorseit, noch afghecort ende ghemindert om al tghemeene verlies, voren verclaerst, ende andre, ende ooc omme de verweecthede bin den voorseiden lande van Waes bi den laetsten orloghe ende andres, IIII s.

Ende aldus dese voorseide twee partien van verliesene te gadre afghesleghen, dien van den voorseiden lande van Waes, draghende in sommen VI s. IIII d., zij bliven betalende van elken hondert ponden in dese subvencien de somme van III lb. XIII s. V d.

Item, es te wetene dat de prochie van Sinte Jans ten Steene metten voorseiden lande van Waes ghelden zal dese waerft in dese voorseide subvencie in der manieren datter toebehoren ende redene gheven zal. 
Item, de stede van Biervliet, die betaelt alle jare in de voorseide rente van den ouden transpoorte XXXI lb., comd up thondert VII s. IX d., daerof afghecort es omme de prochien van den Hamere ende van Sinte Lauwereyns, die metter voorseider stede plaghen te betaelne in allen lasten, die haer overquamen, den vijfsten pennijng, draghende up thondert XVIII d. obole, ende nu al verdronken zijn van der zee ende niet weder te vercrighene in toecommenden tiden. Ende daertoe omme de groote verweecthede ende aermoede van der voorseider stede, die daghelix zeer ghequellet es ende vermindert van der voorseider zee ende anders in menigher manieren ende es al te niet ghescepen, te minderne ende niet te beterne, noch afghecort ende ghemindert II s. II d. obole; dewelke twee partien van verliese ende minderinghe commen te gadre III s. IX d. ende aldus bliven zij betalende van elken hondert ponden in dese subvencie de somme van IIII s.

Item, andre steden, landen ende castelrien, die veraremt zijn ende verweect bi den laetsten orloghe ende anders ende mids dien niet haer last zouden connen ghedraghen, maer zijn vermindert ende daerup voorsien in der manieren hiernaer volghende.

Eerst, de stede van Ghend was ghetaxeert in de voorseide rente van den transpoorte voorseit XIcVIII lb., dat quam up thondert XIII lb. XVII s., daeraf der voorseider stede in de betalinghe van deser subvencie ghemindert ende afghecort es omme der redene, verclaerst int beghinsele van desen capitele, van elken hondert ponden de somme van XVIII d. Aldus bliven zij betalende in dese subvencie van elken honderde als boven XIII lb. XV s. VI d.

\section{Blad 5}

Item, de castelrie van der Ouderbuerch van Ghend betaelt in den voorseiden transpoort IIcXI lb., comd 
up thondert LII s. IX d., daeraf ghemijnct als boven omme dat zij zeer verweect zijn ende verlast van poorters VI s. IX d. Aldus blijftre up thondert als boven XLVI s.

Item, de stede van Curtrike was ghetaxeert in de voorseide rente van den transpoorte voorseit $\mathrm{CXX}$ lb., dat quam up thondert $\mathrm{XXX}$ s., daeraf zij langhe tiden ne maer betaelt heift siaers LXXXIIII lb. XIII s. IIII d., ende tdander, datter ghebreict, heift betaelt over de voorseide stede de castelrie van Curtrike, die daeraf in ditte ende bi deser ordonnance ontlast blijft ende aldus staet de voorseide stede XXX s. up thondert, daeraf ghemijnct ende ghemindert als boven ende omme de redenen voren verclaerst $\mathrm{V}$ s. Aldus blijft er up thondert XXVs.

Item, Ardenbuerch, dat betaelt in den voorseiden transpoort LXIII lb., comd up thondert XV s. IX d., daeraf ghemijnct ende ghemindert als boven ende omme de redenen voren verclaerst, ghemerct de grote destructie ende aermoede van der stede, IX s. IX d. Aldus blijft up thondert VI s.

Item, Oostbuerch, dat betaelt in den voorseiden transpoort XIII lb., comd up thondert III s. III d., daeraf ghemindert omme de aermoede ende verweecthede van der stede IX d. Aldus blijft er up thondert II s. VI d.

Item, Blankenberghe, dat ghelt int voorseide transpoort XV lb., comd up thondert III s. IX d., daeraf ghemindert als boven omme de redenen voren verclaerst, ende dat de voorseide stede meest te nieuten es van den zande van den dunen ende anders, II s. III d. Aldus blijft er up thondert als boven XVIII d.

Itern, Houke, dat ghelt in den voorseiden transpoort LIII s. IIII d., comd up thondert VIII d., daeraf ghemindert als boven omme de aermoede ende verweecthede IIII d. Aldus blijft er up thondert de somme van IIII $d$. 
Item, de stede van Ypre ghelt in den voorseiden transpoort VIIIcLVIII lb., comd up thondert $\mathrm{X}$ lb. XIIII s. VI d., daeraf ghemindert omme tverlies ende destructie van der voorseider stede, die meer dan de heelt ( $\left.{ }^{a}\right)$ ghedestrueirt was in de laetste orloghe van Vlaendren bi den Inghelschen ende anders, XLII s. X d. obole. Aldus blijft er up thondert VIII lb. XI s. VII d. obole.

Item, de castelrie van Berghen ghelt in den voorseiden transpoort IIcLXXIII lb., comd up thondert III lb. VIII s. III d., daeraf ghemindert als boven omme de destructie van der voorseider castelrie bi den laetsten oorloghe ende tlast dat zij ooc zident heift ghehadt van den Inghelschen, mids dat zij zit up de frontiere van den lande, ende nes gheen afslach ghedaen van den verliese van den lande vervloghen van den zande van den dunen in voorseide castelrie, II s. III d. Aldus blijft er up thondert III lb. VI s.

Ende Maerdike, dat ghelt in den transpoort voorseit XXVI s. VIII d. $\left({ }^{b}\right)$, comd up thondert IIII d., daeraf ghemindert omme tverlies ende destructie van den voorseiden laetsten oorloghe, tlaest $\left({ }^{c}\right)$ van den Inghelschen, ende anders als boven I d. obole. Aldus blijft er up thondert II d. obole.

Item, andren steden, landen ende castelrien, die bleven zijn in redeliken state ende omme die redene in dese ordonnance bleven in state zonder ghemindert of ghehoocht te sine up haren rechten transpoort in der manieren hiernaer volghende.

Eerst, de stede van Thoroud ghelt in transpoort voorseit XII lb., comd up thondert III s.

Item, Monekereede ghelt in transpoort voorseit III lb. VI s. VIII d., comd up thondert X d.

$\left({ }^{a}\right)$ Sic, betekent helft. - $\left(^{b}\right)$ VIII d. boven de regel. - $\left(^{c}\right)$ Sic. 
Item, Lombaerdie ghelt in transpoort voorseit IIII lb., comd up thondert XII d.

Ende de stede van Broubuerch betaelt in transpoort voorseit XVI lb., comd up thondert IIII s.

Item, andren steden, landen ende casterien $\left({ }^{a}\right)$, denwelken men haren tax van den voorseiden transpoorte ghehoocht heift, omme dat zij bleven zijn bet in state ende zitten te betre neeringhe, dan eenighe andre bin den voorseiden lande, al eist datter niemene verrijct es, maer alle verweect also voren verclaerst es.

Eerst, de stede ende tland van Denremonde, die ghetaxeert waren int voorseide transpoort CI lb., comd up thondert XXV s. III d., dewelke tax hem omme de voorseide zaken ghehoocht ende ghemeerst es, mids dat zij goeden tax hadden int voorseide transpoort, IIII s. IX d. Aldus zullen zij betalen van elken hondert ponden in de voorseide subvencie de somme van XXX s.

Item, Aelst de stede ende Gheroudsberghe ende tland van Aelst, die ghetaxeert waren int voorseide transpoort VcLIIII lb., comd up thondert VI lb. XVIII s. VI d., die hem ghemeerst zijn omme de redene voorseit XI s., comd te gadre up thondert de somme van VII lb. VIII s. VI d. Item, es te wetene dat de prochie van Steenhuse, gheenclaveert int voorseide land van Aelst, dese waerft in dese voorseide subvencie betalen zal metten voorseiden lande in manieren, datter toebehoren ende redenen gheven sal.

Item, Oudenaerde de stede, die ghelt in transpoorte LV lb., comd up thondert XIII s. IX d., es ghehoocht als boven omme de redenen voren verclaerst $\mathrm{XV} d$. Aldus zullen zij betalen van elken hondert ponden de somme van $\mathrm{XV}$ s.

(a) Sic. 
Item, de castelrie van Oudenaerde, die ghelt in transpoorte LXXXI lb., comd up thondert XX s. III d., es ghehoocht als boven XXI d. omme de causen ende redenen voren verclaerst. Aldus zullen zij betalen van elken hondert ponden XXII s.

Item, de castelrie van Curtrike, die ghetaxeert was ende betaelt int houde transpoort voorseit IIcIIII ${ }^{\mathbf{x x} X V} \mathrm{lb}$. comd up thondert III lb. XIII s. IX d., voor twelke transpoort zij langhe tijt jaerlix betaelt hebben IIIcXXXI lb. VI s. VIII d. ten ontlastene van den transpoorte van der voorseider stede van Curtrike in also verren als zij meer betaelt hebben dan haren rechten tax voorseit, die daeraf in ditte ende bi deser ordonnance ontlast blijft. Ende mids desen zij omme de causen ende redenen boven verclaerst ghehoocht es up thondert XIII s. Aldus sal zij betalen van elken honderde de somme van IIII lb. VI s. IX d.

Item, de stede van Brucghe, die ghelt in transpoorte XIIcXVII lb., comd up thondert XV lb. IIII s. III d., dewelke tax ghemeerst es omme de redenen, verclaerst int beghinsele van desen capitele, X s. Aldus zal de voorseide stede betalen van elken honderde de somme van XV lb. XIIII s. III d.

Item, de stede van den Damme, die ghelt in transpoorte XXXV lb., comd up thondert VIII s. IX d., es ghehoocht als boven III d. Aldus zal de voorseide stede betalen van elken honderde IX s.

Item, de stede van der Sluus, die betaelt in transpoorte LXXVI lb., comd up thondert XIX s., es ghehoocht omme de causen ende redenen voorseit als boven XXI s. Aldus zal zij betalen van elken honderde XL s.

Item, de Mude, die ghelt in transpoorte XL s., comd up thondert VI d., es ghehoocht omme de causen ende redenen voorseit als boven III $d$. Aldus zal zij betalen van elken honderde de somme van IX $\mathrm{d}$. 
Item, de stede van Dixmude, die ghelt in transpoorte LXIX lb. VI s. VIII d., comd up thondert XVII s. IIII d., es ghehoocht omme de causen ende redenen voren verclaerst II s. VIII d. Aldus zal de voorseide stede betalen van elken honderde XX s.

Item, de stede van der Nieuwerpoort metter nieuwer Hyde, die ghelt in transpoorte $\mathrm{L}$ lb., comt up thondert XII s. VI d., es ghehoocht omme de causen ende redenen boven verclaerst XVIII d. Aldus sal de voorseide stede betalen van elken honderde XIIII s.

Item, de stede van Oudembuerch, die betaelt in transpoort XVII lb, comd up thondert IIII s. III d., es ghehoocht omme de causen ende redenen voorseit als boven IX d. Aldus zal zij betalen van elken honderde $\mathrm{V}$ s.

Item, Oosthende, dat ghelt in transpoorte VI lb., comd up thondert XVIII d., es ghehoocht omme de causen ende redenen voorscreven als boven XII d. Aldus zalt betalen van elken honderde II s. VI d.

Blad 6

Item, Ghistele, dat ghelt in transpoorte VII lb., comd up thondert XXI d., es ghehoocht omme de causen ende redenen voorseit als boven III d. Aldus zalt betalen van elken honderden II s.

Item, Vueurne ( $\left.{ }^{a}\right)$ de stede, die ghelt in transpoorte XXVII lb., comt up thondert VI s. IX d., es ghehoocht omme de causen ende redenen voren verclaerst als boven $\mathrm{XV}$ d. Aldus zal zij betalen van elken honderden VIII s.

Item, de castelrie van Vueurne ( $\left.{ }^{a}\right)$, die betaelt in transpoorte III'c LXII lb., comt up thondert IIII lb. X s. VI d., es ghehoocht onme de causen ende redenen voorseit als boven VI d., zonder haer yet te hebbene afghesleghon van den verliese van den lande vervloghen van den zande

(a) Sic. 
van den dunen. Aldus zal zij betalen van elken honderde de some van IIII lb. XI s.

Item, Loo, dat betaelt in transpoorte IIII lb., comd up thondert XII d., es ghehoocht omme de causen ende redenen voorseit als boven III d. Aldus sal betalen $\left({ }^{a}\right)$ van elken honderden de somme van $\mathrm{XV} d$.

Item, Poperinghe, dat betaelt in transpoorte jaerlix IIIIxxXVIII lb., comd XXIIII s. VI d. up thondert, es ghehoocht omme de causen ende redenen voorseit als boven V s. VI d. Aldus salt betalen van elken honderden XXX s.

Item, Berghen de stede, die betaelt in transpoorte XXXV lb., comd up thondert VIII s. IX d., es ghehoocht omme de causen ende redenen voorseit als boven $\mathrm{XV} d$. Aldus sal zij betalen van elken honderden $\mathrm{X}$ s.

Item, de stede van Duunkerke, die betaelt in transpoorte XIX lb., comt up thondert IIII s. IX d., es ghehoocht omme de causen ende redenen voorseit als boven $\mathrm{V} s$. III d. Aldus zal zij betalen van elken honderden $X$ s.

Item, Greveninghe, dat betaelt van transpoorte III lb. VI s. VIII d., comt up thondert $\mathrm{X}$ d., es ghehoocht omme de causen ende redenen voorseit als boven II d. Aldus zal betalen van elken honderden XII d.

Item, de castelrie van Broubuerch, die ghelt in transpoorte LI lb., comt up thondert XII s. IX d., es ghehoocht omme de causen ende redenen voorseit als boven IX $\mathrm{d}$. Aldus sal zij betalen van elken honderden de somme van XIII s. VI d.

Item, de castelrie van Ypre, die betaelt int transpoorte CLXVIII lb., comt up thondert XLII s., es ghehoocht omme de causen ende redenen voorseit als boven II s. Aldus sal zij betalen van elken honderden XLIIII s.

(a) Sic. 
Item, Waestene ende tland, dat betaelt in transpoorte XXX lb., comd up thondert VII s. VI d., es ghehoocht XVIII d., omme de causen ende redenen voorseit als boven. Aldus zullen zij betalen van elken honderden IX s.

Item, Belle de stede, die ghetaxeert es in transpoort VII lb. VI s. VIII d., comd up thondert XXII d.

Ende Belle ambacht, dat ghetaxeert es in transpoort IIIIxxVIII lb., comd up thondert XXII s.

Item, Cassele de stede, die ghetaxeert es in transpoorte III lb., comd up thondert IX d.

Ende Cassele ambacht, dat ghetaxeert es in transpoorte CLXX lb., comt up thondert XLII s. VI d.

Dewelke twee transpoorte draghen te gadre in sommen IIII $\mathbf{x} x X V$ lb. VI $s$. VIII d., comd up thondert XXIII s. $X$ d., zijn beede te gadre ghehoocht teen met andren omme de causen ende redenen voren verclaerst IX s. II d. Aldus zullen zij betalen van elken honderde beede te gadre de somme van XXXIII s.

Dewelke twee transpoorte draghen te gadre in sommen CLXXIII lb., comt up thondert XLIII s. III d., zijn beede ghehoocht teen met andren omme de causen ende redenen voren verclaerst als boven XVI s. IX d. Aldus zullen zij betalen te gadre van elken honderden de somme van III lb.

Item, andre steden ende doorpen, die niet begrepen noch ghetaxeert waren in de rente van den transpoorte voorseit, al eist dat zij minen voorseiden heere ende sinen voorsaten altoos subvencien betaelt hebben up hem zelven in der manieren, dat daertoe behoorde, ende niet 
metten ghemeenen lande van Vlaendren, ghemerct dat zij niet ghetaxeert waren int voorseide transpoort also voorseit es, maer omme dat de voorseide commissie van minen voorseiden heere inhoud, de subvencien voorseit ende costen ommegheset te zine upt ghemeene land van Vlaendren, also voren bliken mach, so zijn zij nu in dese subvencie ende costen voorseit ten avenante van haren state ende goede, dese waerft zonder dat ghetrucken te sine in consequencie in toecommenden tiden noch preiudicie te draghene minen voorseiden heere of zijnre heerlicheit noch andren in toecommen ( $\left.{ }^{a}\right)$ tiden, ghetaxeert in der manieren hiernaer volghende.

Eerst, tland van Bornhem metten dorpen ende andren partien, dertoe behorende ende last draghende met hemlieden in gheliken zaken, es ghetaxeert ende gheset omme de causen ende redenen voorseit in dese zaken up thondert VII s.

Ende Nieneve $\left({ }^{b}\right)$ met Tempelmars ende Vendville, gheleghen in de castelrie van Rijssele ende andre zine toebehoorten, es ghetaxeert omme de causen ende redenen voorseit in dese zaken als boven up thondert de somme van III s. VI d.

Somme dat draghen alle dese taxacie ende partien voorscreven die vergadert al in eene somme : $\mathrm{C} \mathrm{lb}$.

\section{$\S 8$}

Hierna volcht van woorde te woorde thinhouden van eenre andre openre lettre van minen voorseiden heere anegaende den $\mathrm{XX}^{\mathrm{m}}$ dobbelen scilden, daeraf hiervoren int tweeste article van deser rollen mencioen ghemaect es nopende de costen van den commissarisen ende

(a) Sic. - $\left(^{b}\right)$ Niet: Menene, F. Priem-O. Delepierre, o.c., p. 175 . 
ghedeputeirden, hiervoren ghenoomt, ende andre partien, draghende toter sommen van IIImIIIIc X lb (I).

Aldus gheteekent : (2).

\section{Blad 7}

Ende bi viertuten ende cracht van deser lettren voorscreven ende na den inhoudene van dien werden dese waerven ommegheset bi ende up dese voorseide ordonnance up de smale steden, landen ende castelrien ende niet up de viere leden van Vlaendren, boven den voor-

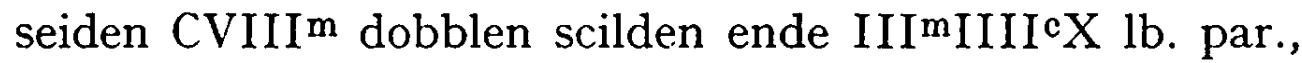
daerof hiervoren mencioen ghemaect es, noch $\mathrm{XX}^{\mathrm{m}}$ dobblen scilde omme de cause ende redenen verclaerst in de voorseide lettren.

\section{$\S 9$}

Allen den ghonen, die dese lettren zullen zien of horen lesen, Jan, heere van der Capelle, Monfrant van Eessine, Jacop Belle, rudders, Robrecht van Cappele, bailliu van Brucghe, Andries van Duway, ontfanghere generael van Vlaendren ende van Artois, David Bousse, meester van der rekeninghe te Rijssele, Dankaerd van Oegerlande, bailliu van Ghent, raden mijns heeren shertoghe van Bourgoingnen, grave van Vlaendren, van Artois ende van Bourgoingnen, Jan van den Kerchove, bailliu van Aelst ende Jan de Hond, castelein, bailliu ende ontfanghere van Bevre, commissarisen in dese zaken, Victor van der Zickele ende Lievin Papal van Ghend, Boudin de Vos, ruddre, heere van Pollaer, ende Lievin de Scotelare van Brucghe, Jan Belle, ruddre, heere van Boesinghen, ende

(I) Hier volgt de oorkonde van Jan zonder Vrees van 31 augustus I 408. Zie tekst 2.

(2) Zie de laatste alinea van tekst 2. 
Andries Paeldijnc dhoude van Ypre, Gillis van der Kercstede dhoude ende Willem van Messeem van den lande van den Vryen, ghedeputeirde van den vier leden van Vlaendren, Ghend, Brucglie, Ypre ende land van den Vryen voorseit, te verstane te dese zaken ende daerover gheroupen na den inhoudene van der opender commissie van onsen voorseiden heere, hiervoren ghescreven, werdichede ende alle vrienscepe.

Doen te wetene $\left({ }^{a}\right)$ dat, omme te werke te doene ende te vulcommene de macht, auctoritet ende bevel, ons ghegheven ende ghedaen bi onsen voorseiden heere ende bi zinen openen lettren van commissien voorseit, die hiervoren in dese rolle ghescreven staen, wij vergadert hebben gheweist tOudembuerch ende daer met groten avise, deliberacie ende voor raden, ons voren wel bevroet bi informacien ende anders van den state, faculte, verliese, commeren ende lasten van den steden, landen ende castelrien van Vlaendren, hebben eendrachteghelike bi ghemeenen acoorde ghemaect, omme dese waerften dordonnance, hiervoren ghescreven in dese jeghewordighe rolle, ende elken van den voorseiden steden, landen ende castelrien, bin den lande van Vlaendren gheseten ende hiervoren verclaerst, haren tax ende grote, ghegheven van der subvencien, daerof voren mencioen ghemaect es, na hare state ende goede ende metten besten besceede, dat wij hebben gheconnen ende moghen na onsen besten vroedomme, macht ende wetenthede; ende eenighe steden verdroghen hierin te taxeerne, omme dat $\mathrm{zij}$ alle verdronken zijn van der zee; eenighe andre ghemindert in partien in de subvencie voorseit, van dat zij deraf betaelt zouden hebben na haren taxe van den ouden transpoorte van Vlaendren; andre ghelaten staen in state zonder minderen of verhoghen; eenighe andre verzwaert

(a) Wetene $B^{1}, B^{2}, C^{2}, B^{3}$; wene $A^{1}$. 
ende ghemeerst haren tax, van dat zij na den voorseiden transpoorte betaelt zouden hebben in de voorseide zaken; ende daertoe tland van Bornhem ende de stede van Nieneve met haren toebehoorten, die niet ghetaxeert waren noch ne betalen in de rente van den transpoorte voorseit noch plaghen te gheldene in eenighen subvencien metten lande van Vlaendren, maer bi hem zelven, als onse voorseide heere ghenouchde yet van hemlieden te hebbene ghetaxeert, zonder preiudicie te draghene in toecommenden tiden in de subvencie voorseit te betaelne in der manieren voorscreven, omme dat zij es omme te settene up tghemeene land van Vlaendren, alsoot blijct bi der voorseider commissie hiervoren; ende verclaerst hoevele dat commen sal up elke van den voorseiden steden, landen ende castelrien voorseit in de voorseide subvencie van CVIII $^{\mathrm{m}}$ dobblen scilden voorseit ende van der voorseider sommen van $\mathrm{III}^{\mathrm{m} I I I I^{c} \mathrm{X}} \mathrm{lb}$. par. ende $\mathrm{XX}^{\mathrm{m}}$ dobbelen scilden, daeraf voren mencion ghemaect es, commen sal te betaelne van elken hondert ponden in der voormen ende manieren ende omme de causen ende redenen hiervoren verclaerst in dese voorseide jeghewordighe rolle ende dat zonder preiudicie van der voorseider renten van den transpoorte voorseit, maer die altoos blivende in state ende in werden, zonder die te minderne of te meersene, alsoot bet verhaelt staet hiervoren int beghinsele van deser rolle voorseit. Van derwelker ende van deser jeghewordigher lettren zijnre ghemaect vive al ghelijc, daeraf onse voorseide heere deene heift ende elc van den voorseiden viere leden eene int ghelike.

$\mathrm{Bi}$ der oorcondscepe van deser lettren, ghegheven onder onse zeghelen uuthanghende, den IX ${ }^{\text {ten }}$ dach van septembre, int jaer ons Heeren M CCCC ende achte. 


\section{INDEX}

\section{AFKORTINGEN en TEKENS}

*: verwijst naar het betrokken woord in de index.

Antw.: België, provincie Antwerpen.

arr. : arrondissement.

dep.: departement.

Fr. : Frankrijk.

fr. : $\quad$ Franse versie.

gem. : gemeente.

grfsch.: graafschap.

hfpl.: hoofdplaats van

knt. : kanton.

N. : noorden.

Ned. : Nederland.

O. : oosten

omschr. : omschrijving.

OVL. : België, provincie Oost-Vlaanderen.

prov. : provincie.

W.: westen.

WVL. : België, provincie West-Vlaanderen.

z: $\quad$ zie; verwijst van de Franse versie naar de Nederlandse.

Z. : $\quad$ zuiden.

ZVL. : Zeeuws-Vlaanderen.

De trefwoorden zijn alfabetisch gerangschikt. Met de, van, van der werd echter geen rekening gehouden.

Aalst, Aelst, Alost, stad ; OVL., hfpl. arr.

AALsT (land van -), tland van Aelst, omschr. in het grfsch. Vlaanderen, bestaande uit de kasselrij Aalst met de steden Aalst en Geraardsbergen.
Aandijke, Adendijc, Ned., Zeeland, ZVL., gem. Zaamslag. AARDENBURG, Ardenbuerch, stad; Ned., Zeeland, ZVL. Aardenburg ambacht, $A r d e n-$ buerch ambocht, omschr. in het Brugse *Vrije. 
Aelst, *Aalst.

Adendijc, *Aandijke.

Aksel, Axele, stad; Ned., Zeeland, $Z V L$.

Aksel ambacht, Axele ambocht, één der *Vier Ambachten; Ned., Zeeland, ZVL.

Alost, *Aalst.

Ardenbuerch, *Aardenburg.

ArTesië, Artois, grfsch. in Noord-Frankrijk.

Artois, *Artesië.

Assenede, OVL., hfpl. knt. Assenede AMBACHT, Asseneder ambocht, Assenedre ambocht, één der *Vier Ambachten.

Athis-sur-Orge, Fr., dep. Seine-et-Oise, arr. CorbeilEssones, knt. Longjumeau. Audembuerch, *Oudenburg. Axele, *Aksel.

Bailleul, z Belle.

Bassevelde, OVL., knt. Kaprijke.

Belle (fr.: Bailleul), stad; Fr., dep. Nord, arr. Duinkerke, hfpl. knt.

BELLE AMBACHT, omschr, in het grfsch. Vlaanderen.

Belle, Ieperse familic. - I) (Jacob), Jaques Belle, ridder, voogd van *Ieper, forestier van Houthulst, raadsheer van de hertog. - 2) - (Jan), ridder; pensionaris, voogd, raad van *Ieper; heer van *Boezinge; gedeputeerde van * Ieper.

Beooster ede, Beooster Ee, landstreek en polder ten $O$. van de Ede (riviertje), ten $O$. van *Aardenburg en ten $Z$. van Sint-Kruis; Ned., Zeeland, ZVL., gem. Aardenburg, e.a.

Berghen, *Sint-Winoksbergen.

Bergues, z Sint-Winoksbergen. Bevere, *Beveren-Waas.

Beveren-WaAs, Bevere, Bevre, OVL., hfpl. knt.

Bevre, *Beveren-Waas.

Bewester EDE, Bewester Ee, landstreek ten $W$. van het riviertje Ede, ten $Z$.O. van *Sluis ; Ned., Zeeland, ZVL., gem. Sluis, e.a.

Biervilet, stad ; Ned., Zeeland, ZVL.

Blankenberge, Blankenberghe, stad; WVL., knt. Brugge. Bleckaerde (ten -), *Blekkaard. BlEKKAARD, ten Bleckaerde, plaats met een molen ten $W$. van *Wenduine en ten $O$. van *Vogeldijke; WVL., knt. Brugge, gem. Wenduine (blekkaard $=$ woeste, onbebouwde duingrond).

Bochoute, *Boekhoute.

Boede (G. de la -), sekretaris van hertog Jan zonder Vrees.

Boekhoute, Bochoute, OVL., knt. Assenede.

Boekhoute Ambacht, Bochoutre ambocht, één der *Vier Ambachten.

BOERGONDIË (fr. : BOURGOGNE) Bourgoingen, Bourgoingnen, grfsch. en hertogdom in Frankrijk.

Boesinghen, *Boezinge.

Boezinge, Boesinghen, Boosinghe, Bousinghe, heerlijk- 
heid ; WVL., knt. Ieper.

*Belle (Jan -).

Boosinghe, *Boezinge.

Bornem, Bornhem, Antw., knt. Puurs.

Botersam, Botersande, *Boterzande.

Boterzande, Botersam, Botersande, eertijds parochie in *IJzendijke- en *Boekhoute ambacht, ten $\mathrm{N}$. van *Biervliet, aan de kust van de *Hont, overstroomd in $\mathrm{I}_{4} \mathrm{O}_{4}$; Ned., Zeeland, ZVL., gem. Hoofdplaat (?)

Bourbourg, z Burburg.

Bourgogne, z Boergondië.

Bourgoingen, Bourgoingnen, *Boergondië.

Bousinghe, *Boezinge.

Bousse (David -), meester van de rekeningen te $\mathrm{Rijsel}$ onder Jan zonder Vrees, maakte zijn hele carrière in de Rekenkamer van Rijsel.

BraAKMAN, eertijds arm van de *Hont, ten O. van *Biervliet ; Ned., Zeeland, ZVL.

Bredenee houc, *Bredenehoek.

BREDENEHOEK, Bredenee houc, WVL., knt. Oostende, gem. Bredene.

Broubuerch, *Burburg.

Brucghe, Bruges, *Brugge.

Brugge, Brueghe, Bruges, stad; WVL., hfpl. prov.

Burburg (fr.: Bourbourg), Broubuerch, stad; Fr., dep. Nord, arr. Duinkerke, hfpl. knt.

BURBURG (kasselrij -), castelrie van Broubuerch, omschr. in het grfsch. Vlaanderen; Fr., dep. Nord.

Calo, *Kallo.

Camerlinx ambocht, *Kamerling ambacht.

Canonike laten, *Kanunnikse (het -).

CAPPEle (Robrecht van -), Robert de Capples, baljuw van *Sint-Winoksbergen (I 8 juli I 399-I 2 jan. I 400), schouteet van *Brugge (1404), baljuw van *Brugge (r407I 4 I I).

CAPPElle, Chapelle, heerlijkheid; WVL., knt. Veurne, gem. Nieuwkapelle. — *Visch (Jan de - ).

Capples (Robert de -), *Cappele (Robrecht van -).

Casant, *Kadzand

CAssel, z Kassel.

Cassele, *Kassel

Chapelle, *Cappelle. _ * Visch (Jan de -).

Chien (Jehan le-), *Hond (Jan de -).

Clemskerke, *Klemskerke.

Clusen, *Kluizen.

Cnocke, *Knokke.

Coudekerke, Couder keerken, *Koudekerke.

Courtivron, heerlijkheid ; Fr., dep. Côte-d'Or, arr. Dijon, knt. Is-sur-Tille. — *Saulx (Jean de -).

Courtray, *Kortrijk.

Curtrike, *Kortrijk.

Damme, stad; WVL., knt. Brugge. 
Dendermonde, Denremonde, stad en kasselrij ; OVL., hfpl. arr.

Denvemonde, *Dendermonde.

Diksmuide, Dixmude, stad; WVL., hfpl. knt.

Dixmude, *Diksmuide.

Douay (Andries van -), Andrieu de Douay, Andries van Duway, pensionnaris van *Ieper, ontvanger-generaal van Vlaanderen en Artesië (vanaf I 406).

Duinkerke (fr. DunkerQue), Duunkerke, stad; Fr., dep. Nord, hfpl. arr.

DUNKergue, z Duinkerke.

Duunkerke, *Duinkerke.

Duway (Andries van -), *Douay (Andries van -).

Eenam, *Ename.

Eessene (Monfrant van -), Monfrant van Eessine, Monfrant d'Essines, ridder, raadsheer van de hertog, soeverein-baljuw van Vlaanderen (I 403-I 405).

ENAME, OVL., knt. \& gem. Oudenaarde. - (kerk van -), kerke van Eenam, bezat "laten" in *Kluizen.

ENGELAND, Ingheland, Engleterre, koninkrijk.

ENGELSEN, Inghelschen.

Engleterre, *Engeland.

EsPIERREs, z Spiere.

Essines (Monfrant d'-), *Eessene (Monfrant van -).

EVERwiJN (Segher -), schepen van de Keure van *Gent, kleine neringen.
Faucille (Victor de la -), Faulchille (Victor de le -), ${ }^{*} \mathrm{Zi}$ ckelen (Victor van der -).

Filips de Stoute, hertog van *Boergondië, graaf van *Vlaanderen (1384-I 404), *Artesië, *Boergondië en Rethel, heer van *Salins en *Mechelen; huwde met Margareta van Male, dochter van Lodewijk van Male.

Flandres, *Vlaanderen.

Franc (terroir $d u-$ ), *Vrije (het Brugse -).

Gand, Gant, *Gent.

GATERNISSE, Gaternesse, plaats ten N.O. van Schoondijke in de Prins-Willempolder ; Ned., Zeeland, ZVL., gem. Schoondijke.

Gent, Ghend, Ghent, Gand, Gant, stad ; OVL., hfpl. prov. GENr (Zeger van -), Zegher van Ghend, ridder, derde echtgenoot van Margareta, bastaarddochter van Lodewijk van Male; bezat "laten" in * Kluizen.

GentstraAt (?), Gheyns strate, Ned., Zeeland, ZVL., gem. Biervlict.

GeraARDSBergen, Gheroudsberghe, stad; OVL., hfpl. knt.

Ghend, Ghent, *Gent.

Gheroudsberghe, *Geraardsbergen.

Gheyns strate, *Gentstraat.

Ghistele, *Gistel.

Gistel, Ghistele, stad; WVL., hfpl. knt. 
Gravelines, $z$ Greveningen.

Greveningen (fr.: GraveliNES), Greveninghe, stad ; Fr., dep. Nord, arr. Duinkerke, hfpl. knt.

GRUTERE (Simon de -), Symoen de Grutere, bezat "laten" in * Kluizen.

HAMer (de -), den Hameve, plaats bij *Biervliet; Ned., Zeeland, ZVL., gem. Biervliet.

Harendike, *Tarrendijke.

Heist, Heis, WVL., knt. Brugge.

HELMARE, waterloop en gehucht met een priorij van SintPieters (Gent), ten Z.W. van *IJzendijke ; Ned., Zeeland, ZVL., gem. Waterlandkerkje.

Heyns (Pieter -), controleur van de rekeningen van de hertog (vanaf I390), controleur van de rekeningen van de officieven van Vlaanderen (vanaf I 394).

HoEke, Houke, eertijds stad, thans dorp; WVL., knt. Brugge.

HoND (Jan de -), Jehan le Chien, ontvanger van de kasselrij L'Ecluse (r396-r399) (L'Ecluse, Fr., dep. Nord, arr. Douai, knt. Arleux.), burggraaf, baljuw en ontvanger van *Beveren-Waas.

HoNr, of Wester-Schelde, zuidelijke monding van de Schelde.

Houke, *Hoeke.
Hugevliet, Hughevliete, eertijds stad aan de *Hontekust, ten N.O. van Schoondijke, tussen Breskens en Hoofdplaat, verdronken in $\mathrm{I}_{4} \mathrm{O}_{4}$; Ned., Zeeland, ZVL.

Hulst, stad; Ned., Zeeland, ZVL.

Hulst Ambacht, Hulstre ambocht, Ulstre ambocht, één der *Vier Ambachten ; Ned., Zeeland, ZVL.

Huutkerke, *Uitkerke.

Hyde, WVL., knt. \& gem. Nieuwpoort.

IEPER, Ypre, Yppre, stad; WVL., hfpl. arr.

IEPER (kasselrij -), castelrie van Ypre, omschr. in het grfsch. Vlaanderen; WVL.

I JZENDIJKE, Ysendike, stad, verdronken in $\mathrm{I}_{4} \mathrm{O} 4$; Ned., Zeeland, ZVL.

IJZENDIJKE AMBACHT, tambocht van Ysendike, omschr. in het Brugse *Vrije.

Ingheland, *Engeland.

Inghelschen, *Engelsen.

JAN ZONDER VREES, Jehan, duc de..., hertog van *Boergondië, graaf van *Vlaanderen, *Artesië en *Boergondië, heer van *Salins en *Mechelen (I405-I4I9), voordien graaf van Nevers; zoon van *Filips de Stoute en Margareta van Male.

Jehan, duc de..., *Jan zonder Vrees.

JULIEN, Bruggeling. 
Kadzand, Casant, Ned., Zeeland, ZVL.

Kallo, Calo, OVL., knt. Beveren-Waas.

Kamerling AmbaCHT, Camerlinx ambocht, omschr. in het Brugse *Vrije (WVL.), bestaande uit de dorpen Leffinge, Slijpe, Snaaskerke en Wilskerke (knt. Gistel) ; Mannekensvere, Middelkerke en Westende (knt. Nieuwpoort) ; en Stene (knt. Oostende).

KANUNNIKSE (het -), Canonike laten, heerlijkheid, afhangend van de kanunniken van het *Sint-Donaaskapittel van Brugge, verspreid over het Brugse *Vrije (WVL.).

Kassel (fr.: Cassel), Cassele, stad; Fr., dep. Nord, arr. Duinkerke, hfpl. knt.

KASSEL AMBACHT, Cassele ambacht, omschr. in het grfsch. Vlaanderen ; Fr., dep. Nord. Kerchove (Jan van den -), Jehan de Latre, schepen van de Keure en van Gedelen van *Gent, baljuw van *Aalst. KerCstede de oude (Gillis van der -), Gille de le Kercstede le viel, burgemeester van de commune en van de schepenen van het Brugse *Vrije, gedeputeerde van het Brugse *Vrije.

KieldRECHT, OVL., knt. Beveren-Waas.

KLemskerke, Clemskerke, WVL., knt. Brugge.

Kluizen, Clusen, OVL., knt. Assenede.
KNoккE, Cnocke, WVL., knt. Brugge.

Koczide, *Koksijde.

Koezand, oorspronkelijk, eiland in de monding van de *Hont ten O. van *Wulpen en *Waterdunen, later één eiland vormend met $*$ Wulpen, tenslotte verdronken; Ned., Zeeland.

Koksijde, Koczide, eertijds haven en dorp tussen *Sluis en *Oostburg, verdronken in I 404 ; Ned., Zeeland, ZVL. Kortrijk, Curtrike, Courtray, stad; WVL., hfpl. arr.

KorTRIJ K (kasselrij -), castelrie van Curtrike, omschr. in het grfsch. Vlaanderen; WVL. \& OVL.

KoUdeKerke, Coudekerke, Couder keerken, eertijds dorp ten $O$. van *Biervliet aan de oostzijde van de latere *Braakman ; Ned., Zeeland, ZVL., gem. Hoek (?).

Lancardenbuerch, *Langaardenburg.

LANGAARDENBURG, Lancardenbuerch, eertijds stad, verdronken ca. I375; OVL., knt. Kaprijke, gem. Waterland-Oudeman (?)

LAREE (de -), certijds waterloop en gehucht van *Koudekerke, ten $O$. van *Biervliet, aan de oostzijde van de latere *Braakman ; Ned., Zeeland, ZVL.

Latve (Jehan de -), *Kerchove (Jan van den - ). 
Lille, *Rijsel.

LISSEWEGE, WVL., knt. Brugge.

LISSEWEGE AMBACHT, Lisseweghe ambocht, omschr. in het Brugse *Vrije, bestaande uit *Heist, * Knokke en *Lissewege.

Lo, Loo, stad ; WVL., knt. Roesbrugge-Haringe.

Lombaerdie, *Lombardsijde.

LOMBARDSIJDE, Lombaerdie, eertijds stad thans dorp; WVL., knt. Nieuwpoort.

Loo, *Lo.

Maerdike, *Mardijk.

Malines, *Mechelen.

Mardijk (fr.: Mardyck), Maerdike, eertijds stad thans dorp; Fr., dep. Nord, arr. $\&$ knt. Duinkerke.

MARDYCK, z Mardijk.

Mechelen, Malines, stad; Antw., hfpl. knt.

Melsele, Melseele, OVL., knt. Beveren-Waas.

Messeem (Willem van -), Guillaume de Messem, schepen en ontvanger van het Brugse *Vrije; gedeputeerde van het Brugse *Vrije.

Messem (Guillaume de-), *Messeem (Willem van -).

Moermanspolder, Moermans polve, polder in *Aksel ambacht ; Ned., Zeeland, ZVL.

Monekereede, *Monnikerede.

Monnikerede, Monekereede, eertijds stad aan het ${ }^{*} Z$ win ten $Z$. van *Hoeke; WVL., knt. Brugge, gem. Oostkerke.
Mortagne (Hendrik van -), ridder, heer van *Spiere, gezant en raadsheer van *Filips de Stoute, lid van de Raadkamer van Rijsel, kapitein van *Brugge en het Brugse *Vrije.

Mude, *Sint-Anna-ter-Muiden.

Nieneve, *Ninove.

Nieuwerpoort, *Nieuwpoort.

NiEUWPOORT, Nienwerpoort, stad; WVL., hfpl. knt.

Ninove, Nieneve, stad; OVL., hfpl. knt.

Noordrolder, Noord poolve, polder ten $N$. van *Aksel; Ned., Zeeland, ZVL.

Oegerlande (Dankaerd van -), * Ogierlande (Dankaard van $-)$.

OGIERLANDE (Dankaard van -), Dankaerd van Oegerlande, Dankaerd d'Ogierlande, Danckaert de Ogierlande, baljuw van *Sluis ( $1387-1389$ ), baljuw van *Gent (I389-I4II).

Oostbuerch, *Oostburg.

OOSTBURG, Oostbuerch, stad ; Ned., Zeeland, ZVL.

OOSTBURG AMBACHT, Oostbuerch ambocht, omschr. in het Brugse *Vrije; Ned., Zeeland, ZVL.

OosteekLo, Oosteeclo, OVL., knt. Kaprijke.

OOSTENDE, Oosthende, stad; WVL, hfpl. knt.

Ossenisse, Ossenesse, Ned., Zeeland, ZVL., gem. Vogelwaarde. 
OTENE, verdeeld in Nieuwen Oud-Otene; Ned., Zeeland, ZVL., gem. Zaamslag. OUDBURG VAN GENT, Ouderbuerch van Ghend, omschr. in het grfsch. Vlaanderen; OVL.

OUDENAARDE, Oudenaerde, stad ; OVL., hfpl. arr.

OUdENAARDE (kasselrij -), castelrie van Oudenaerde, omschr. in het grfsch. Vlaanderen; OVL.

Oudembuerch, Oudenbuerch, * Oudenburg.

OUdenburg, Audembuerch, Oudembuerch, Oudenbuerch, stad; WVL., knt. Gistel.

Ouderbuerch, *Oudburg.

Paeldinc de oude (Andries -), Andries Paeldijnc dhoude, Andrieu Paeldinc le viel, gedeputeerde van *Ieper.

Panne (de -), plaats ten $O$. van *Heist; WVL., knt. Brugge, gem Heist.

Papal (Lieven -), Lievin Papael, Lievin Papil, gedeputeerde van *Gent.

Papil (Lievin -), *Papal (Lieven - ).

Pollaer, Pollar, *Pollare.

Pollare, Pollaer, Pollar, heerlijkheid; OVL., knt. Ninove. - Vos (Boudewijn de -)

Pontoise, Fr., dep. Seine-etOise, hfpl. arr.

Pofrringe, Poperinghe, stad; WVL., hfpl. knt.

REIGERSVLIET, Reingaertsvliete, watering en heerlijk- heid tussen *Knokke en *Heist, voordien aan een inham van, het Oude $Z$ win; WVL., knt. Brugge, gem. Westkapelle \& Knokke.

Reingaertsuliete, *Reigersvliet. RIET (het -), tRiet, waterloop en plaats bij *Boekhoute; OVL., knt. Assenede, gem. Boekhoute (?)

RiJSEL, Lille, stad; Fr., dep. Nord, hfpl. dep.

RiJSEL (kasselrij-), castelvie van Rijssele, omschr, in WaalsVlaanderen; Fr., dep. Nord. ROESELARE, eertijds stad, verdronken ca. r376; OVL., knt. Kaprijke, gem. SintMargriete (?)

Salins, heerlijkheid; Fr., dep. Jura, hfpl. knt.

Saulx (Jean de -), J. de Saulz, seigneur de Courtivron, kanselier van *Boergondië, heer van ${ }^{*}$ Courtivron.

Scotelare (Lievin le -), *Scuetelare (Lieven de -).

Scuetelare (Lieven de -), Lievin le Scotelave, burgemeester van de schepenen en raden van *Brugge, schepen, raad en hoofdman; gedeputeerde van *Brugge.

Sint-ANnA-TER-MUIden, $\quad M u$ $d e$, eertijds stad aan het *Zwin, tegenover *Sluis ; Ned. Zeeland, ZVL., gern. Sluis. Sint-DonaAs, kapittel te Brugge.

Sinte Jans ten Steene, *SintJansteen. 
Sinte Lauwereyns, *SintLaureins.

Sint-Jansteen, Sinte Jans ten Steene, Ned., Zeeland, ZVL.

Sint-Katelijne, Sinte Kateline, WVL., knt. Brugge, gem. Knokke.

Sint-Laureins, Sinte Lauwereyns, OVL., knt. Eeklo.

SINT-WINOKSBERGEN (fr.: Bergues), Berghen, stad ; Fr., dep. Nord, arr. Duinkerke, hfpl. knt.

Sint-Winoksbergen (kasselrij -), castelrie van Berghen, omschr. in het grfsch. Vlaanderen ; Fr., dep. Nord.

Sluis, Sluus, stad; Ned., Zeeland, ZVL.

Sluus, *Sluis.

Spiere (fr. Espierres), Henegouwen, knt. Moeskroen. *Mortagne (Hendrik van -). SpIERINC (Sander -), schout van *Brugge (1387-I394), baljuw van *Brugge (I 394I 399), soeverein-baljuw van *Vlaanderen (I 402-I 403).

StaARTe, Staerte, Strate, eertijds vissersdorp in de watering van * Reigersvliet; WVL. knt. Brugge, gem. Knokke.

Steenhuize, Steenhuse, OVL., knt. Nederbrakel, gem. Steenhuize-Wijnhuize.

Steenhuse, *Steenhuize.

Strate, *Staarte.

TARRENDIJKE, Havendike, eertijds dorp ten $O$. van *Wenduine in *Uitkerke ambacht;
WVL., knt. Brugge., gem. Wenduine.

Tempelmars, *Templemars.

Templemars, Tempelmars, Fr., dep. Nord, arr. Rijsel, knt. Seclin.

Thoroud, *Torhout.

Tolin zant, zandplaat bij *Vlissegem; WVL., knt. Brugge, gem. Vlissegem.

TORHOUT, Thoroud, stad; WVL. hfpl. knt.

Uitkerke, WVL., knt. Brugge. UITKERKF. AMBACHT, ambocht van Huutkerke, omschr. in het Brugse *Vrije, bestaande uit *Wenduine, *Uitkerke en Sint-Jans-op-den-Dijk (gem. Uitkerke).

Ulstre ambocht, *Hulst ambacht.

Vendeville, Vendville, Fr., dep. Nord, arr. Rijsel, knt. Seclin. Vendville, *Vendeville.

VERREBROEK, Verrebrouc, OVL. knt. Beveren-Waas.

Verrebrouc, *Verrebroek.

VEURNE, Vueurne, stad ; WVL., hfpl. arr.

VEURNE (kasselrij -), castelrie van Vueurne, omschr. in het grfsch. Vlaanderen; WVL. VIER AMBACHTEN, Vieve $A m$ bochten, omschr. in het grfsch. Vlaanderen, bestaande uit *Aksel -, *Assenede-, *Boekhoute - en *Hulst ambacht. VIJFHUIZEN, ten Vijfhuuse, dorp bij *Volkaartsgote, ten $O$. 
van *Knokke; WVL., knt. Brugge, gem. Knokke.

Vijfhuuse (ten -), *Vijfhuizen. VINX AMBACHT, sVinx ambocht, omschr. en watering in het Brugse *Vrije tussen *Oostende en *Blankenberge.

Visch (Jan de -), sire de la Chapelle, ridder, heer van *Cappelle, raadsheer van de hcrtog, soeverein-baljuw van *Vlaanderen (I386-I 390).

Vischersdoorp, *Vissersdorp.

VISSERSDORP, Vischersdoorp, voormalig dorp ten $\mathrm{N}$. van *Biervliet, aan de kust van de *Hont; Ned., Zeeland, ZVL., gem. Hoofdplaat (?)

VlaANDEREN, Vlaendren, Flandres, graafschap.

Vlaendren, *Vlaanderen.

VLISSEGEM, Vlissegheem, WVL., knt. Brugge.

Vlissegheem, *Vlissegem.

VOGELDIJKE, Vogheldike, gehucht ten W. van *Blekkaard en van *Wenduine, tussen *Wenduine en *Vlissegem; WVL., knt. Brugge, gem. Wenduine.

VOLKAARTSGOTE, Volkaerts Gho$t e$, watering ten $O$. van * Knokke bij *Vijfhuizen; WVL., knt. Brugge, gem. Knokke.

Vos (Boudewijn de -), Boudin de Vos, Bauduin le Vos, ridder, heer van *Pollare; gedeputeerde van *Brugge. VRIJE (het Brugse -), lande van den Vryen, terroir du Franc, omschr. in het grfsch. Vlaanderen.
Vryen (lande van den -), *Vrije (het Brugse -).

Vueurne, *Veurne.

WAAS (land van -), tland van Waes, omschr. in het grfsch. Vlaanderen; OVL.

WAasten (fr.: WARNETON), Waestene, stad en land; $\mathrm{He}-$ negouwen, arr. Moeskroen. Waes (tland van -), *Waas (land van -).

Waestene, *Waasten.

WARNETON, z Waasten.

WATERDUNEN, eertijds stad op afzonderlijk eilandje tussen de eilanden *Wulpen en *Koezand, aan de noordzijde, verdronken $3^{\mathrm{e}}$ kwart XIVe eeuw; Ned., Zeeland.

WATERVIIET, OVL., knt. Kaprijke.

WenduINe, Wendunen, WVL., knt. Brugge.

Wendunen, *Wenduine.

Wevelswale, eertijds dorp ten N.O. van ${ }^{*}$ Biervliet in de monding van de latere *Braakman; Ned., Zeeland, ZVL.

WOUTERMANS AMBACHT, sheere Woutermans ambocht, omschr. in het Brugse ${ }^{*}$ Vrije bestaande uit Bredene, Ettelgem, Mariakerke (gem. Oostende), Oudenburg-buiten en Zandvoorde ; WVL., knt. Oostende \& Gistel.

WULPEN, verdronken eiland ten N. van *Kadzand; Ned., Zeeland. 
Ypre, Yppre, *Ieper.

Ysendike, ${ }^{*}$ I Jzendijke.

Zickelen (Victor van der -), Victor de la Faucille, Victor de le Faulchille, gedeputeerde van *Gent.

ZwiN, zeearm in het $N$. van het Brugse *Vrije, met uitmonding tussen ${ }^{*}$ Knokke en * Kadzand. 